تقتين مقياس ما وراء الفهم في الرياضيات لاى طلاب الصف الأول الثانوي

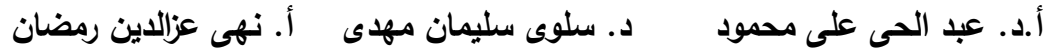

\title{
تقنين هقياس ها وراء الفهم في الرياضيات لدى طلاب الصف الأول الثانوي
}

\author{
إعداد
}

د. سلوى سليمان مهدى

مدرس علم التفس التريوي

كلية التربية - جامعة أسوان

salwa_elmahady@yahoo.com

\author{
أ.د. عبد الحى على محمود \\ أستاذ علم النفس التربوي المتفرغ \\ كلية التربية - جامعة أسوان \\ agaderabdelhay@yahoo.com
}

\section{أ. نهى عزالدين رمضان \\ معيدة بقسم علم النفس التريوى \\ كلية التربية - جامعة أسوان}

noha.eizeldinramadan@gmail.com 
تقنين مقياس ما وراء الفهم فى الرياضيات لدى طلاب الصف الأول الثانوى

$$
\text { دلد / سلوى سليمـان مهدى علم النفس التربوى }
$$

salwa_elmahady@yahoo.com

$$
\begin{aligned}
& \text { د / عبدالحى على محمود } \\
& \text { أستاذ علم النفس التريوى المتفرغ عائ } \\
& \text { كلية التربية - جامعة أسوان }
\end{aligned}
$$

agaderabdelhay@yahoo.com

$$
\begin{aligned}
& \text { أ/ نهى عزالدين رمضان } \\
& \text { معيدة بقسم علم النفس التريوى } \\
& \text { كلية التربية - جامعة أسوان }
\end{aligned}
$$

noha.eizeldinramadan@gmail.com

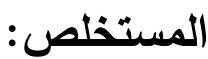

هدف البحث إلى تقنين مقياس ما وراء الفهم فى الرياضيات لدى طلاب الصف

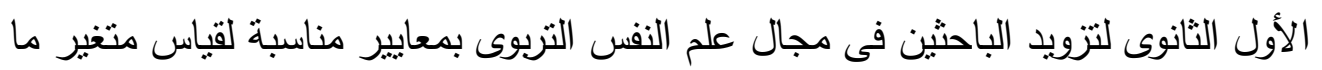

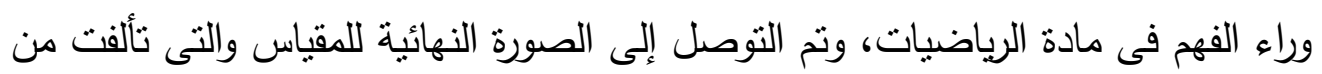
(ب0) عبارة موزعة على خمسة أبعاد أساسية وهى (النتظيم- التقييم- الوعى بالقدرة الذانية

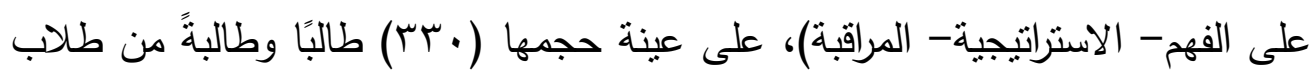
الصف الأول الثانوى العام، تم حساب صدق المقياس باستخدام طريقة الصدق العاملى بطريقة المكونات الأساسية مع التدوير المائل Direct Oblimin، وأسفرت نتائج التحليل العاملي عن وجود خمسة عوامل تتبعت عليها عبارات المقياس وهى (التتظيم- التقييمالوعى بالقرة الذانية على الفهم- الاستراتيجية- المراقبة، وتم حساب الثبات لمقياس

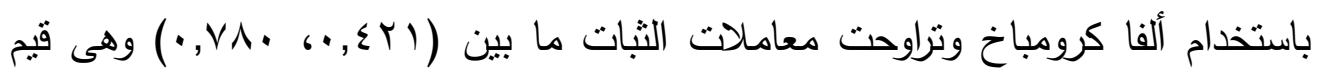
مرتفعة مما يدل على ثبات أبعاد مقياس ما وراء الفهر.

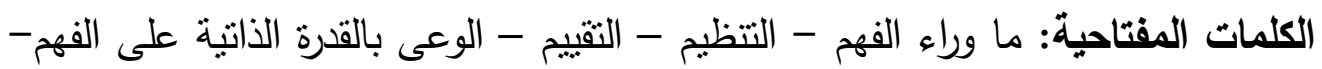

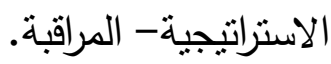




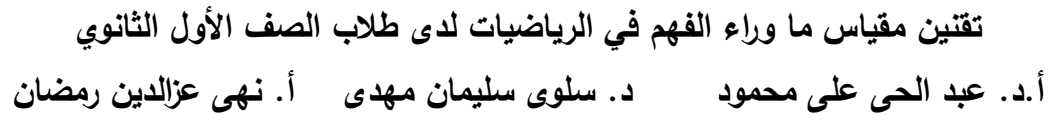

\section{Regulating the Scale of Metacomprehension in Mathematics of the $1^{\text {st }}$ Grade Secondary School Students}

\author{
Prof. / Abdalhai Ali Mahmoud \\ Tenured Professor of Educational Psychology \\ Faculty of Education, Aswan University \\ agaderabdelhay@yahoo.com
}

\author{
Dr. / Salwa Soliman Mahdi \\ Educational Psychology Lecture \\ Faculty of Education, Aswan University \\ salwa_elmahady@yahoo.com
}

Noha Eizeldin Ramadan

Demonstrator at Aswan Faculty of Education

Faculty of Education, Aswan University

noha.eizeldinramadan@gmail.com

\section{Abstract:}

The research aimed at regulating the scale of metacomprehension in mathematics of the $1^{\text {st }}$ grade secondary school students, to provide the researchers of the educational psychology with suitable standards to measure the variable of the metacomprehension in mathematics.

It was reached the final form of the scale which is consisted of (35) phrases, distributed on (5) main components (the monitoring the strategy -the Evaluation - the regulation - Awareness of the ability to understand). The sample of the research consisted of (330) $1^{\text {st }}$ grade secondary school students.

The scale validity was measured by using the factor analysis (principal component analysis with Direct Oblimin rotation). The results of the factor analysis revealed the existence of (5) factors: the monitoring - the strategy - the regulation -Evaluation - Awareness of the ability to comprehension.

The scale reliability was measured by using Cronbach's alpha. The reliability factors were ranged between $(0.421: 0.780)$ which means that the metacomprehension scale components are reliable.

Keywords: Meta-comprehension - Monitoring Evaluation - Strategy -Awareness of the ability to comprehension - Regulation. 
تقتين مقياس ما وراء الفهم في الرياضيات لاى طلاب الصف الأول الثانوي

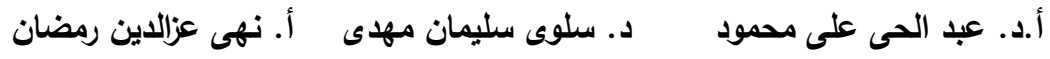

مقدمة:

يتميز العصر الحالى بالانفجار المعرفى والتطور العلمى السريع، حيث يواجه المتعلمون كماً هائلاً من المعلومات والمعرفة فى كل لحظة تمر ، مما يُحتم عليهم امتلالك بله مقومات المنهج العلمى السليم ومعرفة طرق الحصول على هذه المعلومات وفهمها واستيعابها بعيداً عن الحفظوالتلقين، وبذلك يتم التحول من ثقافة تلقى المعلومة إلى ثقافة بنائها ومعالجتها وتحويلها إلى معرفة تتمثل فى اكتتاف علاقات وظواهر جديدة. ويعتبر الفهم هو أساس التعلم، لذلك يجب أن يتحقق الفهم لدى كل متعلم فى

ضوء إمكاناته وقدراته ونمط تعلمه المفضل. ويُشار إلى الفهم من الناحية السيكولوجية بأنه إدرالك العلاقات القائمة فى موقف يجابهه الفرد، والفهم الجيد لما يقدَّم للطلاب من معلومات فى إطار المواد الدراسية يكسبهم القدرة على الاحتفاظ بها واستخدامها بشكل إيجابى وجيد وصحيح فى

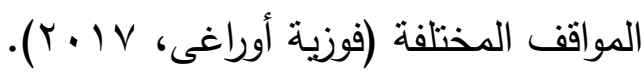

ولمَّا كانت الرياضيات تقوم فى أساسها على الفهم والاستيعاب، فهى تعد ضرباً من ضروب التقكير المجرد الذى يعتمد على الرموز بدلاً من المحسوسات، وهى كذلك

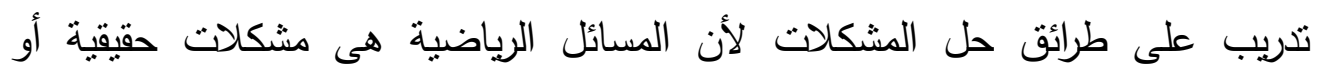
افتراضية لذلك فإن واضعى مناهج الرياضيات والاختصاصيين فى طرائق وأساليب تدريسها يؤكدون أن الرياضيات أسلوب فى التفكير أساسه الفهم وإدرالك العلاقات والاستدلال، فبينيتها الخاصة وتراكينها فى تقديم مواضيعها يمثل الفهم أساساً لها نقوم عليه وتنبى عليه خبراتها وموضوعاتها.(Rittle-Johnson, Siegler \& Alibali, 2001) ويتطلب الوصول إلى الفهم وعى الفرد بما يتعلمه بالإضافة إلى معرفة ما يجب

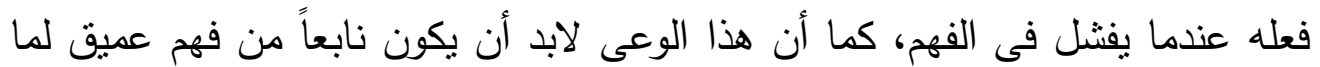
يتعلمه الفرد من خلال مراقبته لعمليات الفهم المختلفة لديه، وهو ما يعبر عنه بما وراء الفهم Metacomprehension. 
تقتين مقياس ما وراء الفهم في الرياضيات لدى طلاب الصف الأول الثانوي

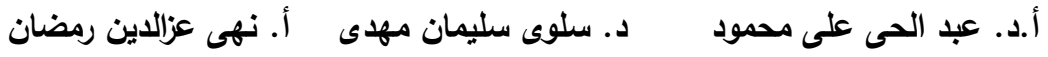

ويشير مفهوم ما وراء الفهم إلى قدرة الفرد على الحكم على ما تعلم وقدرته على

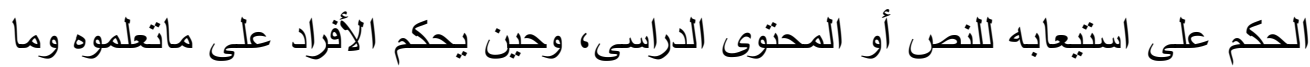
لم يتعلموه سيكون بمقدرهم تركيز انتباههم على المعلومات التى لم يتعلموها .\& Anderson, 2003) وذكر Zhao \& Linderholm أن القدرة على التبؤ بمستوى الفهم أو الحكم على مدى الفهم لدى المتعلمين يعتبر المحور الرئيسى لموضوع ما وراء الفهم، وتعد تلاك القدرة مهمة للتتظيم الذاتى للدراسة، فعندما يتتبأ الطلاب بأنهم سيؤدون أداءاً

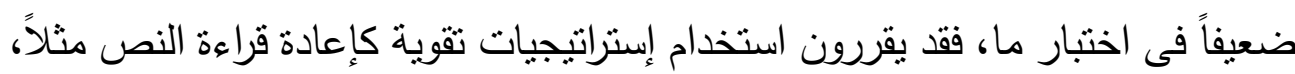
وقد بينت الدراسات أن أحكام ما وراء الفهم الأكثر دقة تؤدى إلى تتظيم ذاتى أكثر فعالية للاراسة والذى يقود بدوره لتعلم أفضل. وبذللك يحتل موضوع الوعى بإستراتيجيات التعلم بصفة عامة، ومهارات ما وراء الفهم بصفة خاصة أهمية كبيرة فى انتقال الطلاب من مستوى التعلم الكمى إلى مسنوى لئى

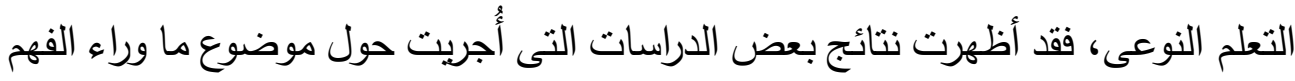
إلى وجود ارتباط موجب ذى دلالة إحصائية بين درجة وعى الطلاب بما يتعلمونه ويستخدمونه من أساليب وفنيات وعمليات قرائية ومدى إدراكهم وتذكرهم للمعلومات وقدرتهم على استخدامها وتوظيفها فى مواقف التعلم المختلفة Rawson, Dunlosky) .\& McDonald, 2002) وتعد مهارات ما وراء الفهم أحد أهم العوامل المؤثرة فى تتمية البناء المعرفى والنسق الفكرى لاى الطلاب فى مختلف مراحل التعليم، ولمَّا كانت مهارات ما وراء الفهم فى ماهيتها عملية تفاعلية بنائية، فإن هذا الفهم الواسع لن يتحقق إلا إذا توافر لاى الطلاب قدر من الوعى باستخدامها وكذلك الوعى بالنشاطات الذهنية والعمليات

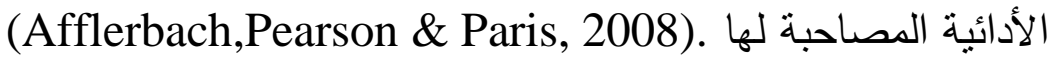
وقد حدد ستانفورد أربع مستويات تشكل الفهم وما وراء الفهم: 
تقتين مقياس ما وراء الفهم في الرياضيات لاى طلاب الصف الأول الثانوي

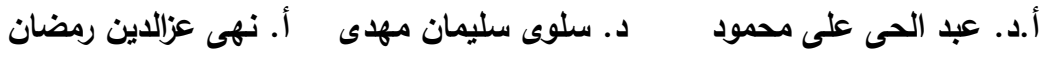

- المستوى الأول: (فهم عال - ما وراء فهم عال) وهم الطلاب الذين لديهم القدرة على الفهم ويدركون أن الفهم قد نم ويعتقدون أن أدائهم سيكون جيداً فى

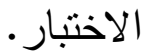

- المستوى الثانى: (فهم منخفض وما وراء فهم مرتفع) وهم الطلاب ضعاف الفهم ولكنهم يدركون فثلهم فى الفهم، ويعتقدون أن أدائهم سيكون ضعيفاً فى وهى ونى

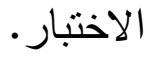

- المستوى الثالث: (فهم مرتفع - ما وراء فهم منخفض) وهم طلاب لديهم القدرة على الفهر ولكنه غير منأكدين من فهمه أو من عدمه وهم ذوو أداء جيد فى الاختبار ويعتقدون أن أدائهم ضعيف.

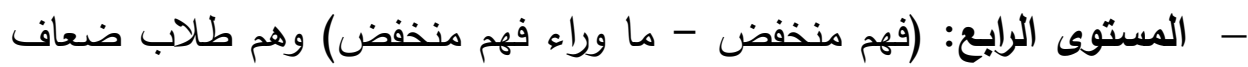
الفهم ولكنهم لا يدركون أسباب فثلهم فى الفهم، وقد يكون أداؤهم ضعيفاً فى الاختبار ولكنهم يعتقدون أن أدائهم كان جيداً \& Thiede, Anderson, \&

.Therriault, 2003)

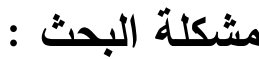

ظهر الاهتمام بالفهم من خلال بعض المشاريع التربوية منل مشروع زيرو zero project) (Harvard) أثنارت نتائج البحوث والدراسات فى هذا المشروع إلى أن الدرجة العادية من الفهر مفتقَّة لاى كثثبر من الطلاب حتى عند أفضل الطلاب الذين يبدو أنهم يفهون المادة التى تدرس فى الفصل كما تشير نتائج الاختبارات والمناقثة الصفية (جابر عبدالحميد، $\cdot(r \cdot r$

كما أظهرت نتائج دراسة Erbas \& Okur (2012) أن النجاح فى حل المشكلة الرياضية عملية معقدة لا يعزو السبب فى التغلب عليها لسلوك واحد، وحتى ينجح الطلاب فى حل المشكلة الرياضية ينبغى عليهم أن يمتلكوا المعرفة الرياضية 
تقتين مقياس ما وراء الفهم في الرياضيات لاى طلاب الصف الأول الثانوي

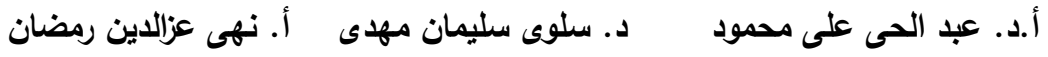

المطلوبة، ومعرفة كيفية استخدام الإستراتيجيات المختلفة مع مراقبة حل المشكلة وتتظيمها باستخدام مهاراتهم الما وراء معرفية (نوال الراجح، 10 • ب). لذا يجب التعرف على مفهوم ما وراء الفهم فى الرياضيات والتعرف على أبعاده وعوامله والأسس التى يتزتب عليها، فمعظم أبحاث ما وراء الفهم ركزت على الفهم والقراءة (Maltin, 2009, p. 193).

كما أنه لا نوجد أداة علمية تم بناؤها وتقنينها خصيصاً للبيئة المصرية وطلاب المرحلة الثانوية لقياس ما وراء الفهم فى الرياضيات، لذا يسعى البحث الحالى إلى إعداد

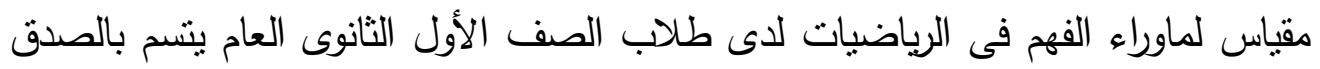
والثبات.

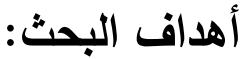

يسعى البحث لتحقيق الأهداف التالية:

- - بناء مقياس لماوراء الفهم فى الرياضيات لدى طلاب الصف الأول الثانوى العام. - - التعرف على أبعاد ما وراء الفهم فى الرياضيات لدى طلاب الصف الأول الثانوى العام. - - التعرف على الخصائص السيكومترية لمقياس ماوراء الفهم فى الرياضيات لدى طلاب الصف الأول الثانوى العام. مصطاحات البحث: عرَّف (2003).Thiede, et al ما وراء الفهم بأنه قدرة الفرد على الحكم على ما تعلمه وما لم يتعلمه، ومن ثم يستطيع تركيز انتباهه على المعلومات التى لم يتعلمها، وإذا كانت دقة ما وراء الفهم لديه ضعيفة، فلن بتمكن من استخدام أحكامه فى توجيه التعلم بشكل صحيح. كما عرَّفه (2007) Dunlosky \& Lipko بأنه قدرة المتعلم على الحكم على تعلمه وفهمه لمحتوى المواد الدراسية. 
تقتين مقياس ما وراء الفهم في الرياضيات لاى طلاب الصف الأول الثانوي

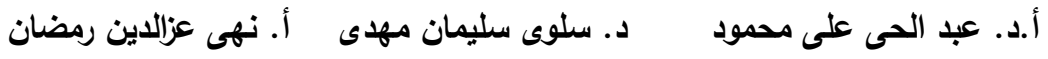

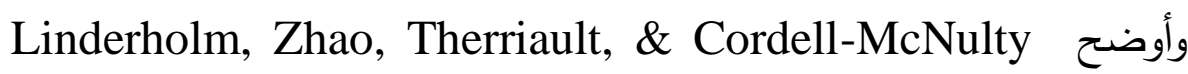
(2008) أن ما وراء الفهم يشير إلى السيطرة والمراقبة التى يقوم بها المتعلم عندما يقيّمٍ مستوى فهمه فى أثناء التعلم.

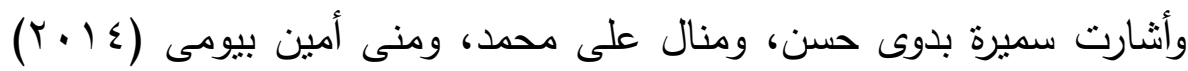
إلى أن ما وراء الفهم يعنى وعى الفرد ومعرفته بالنصوص المراد فههيا وبإستراتيجيات أدائه ومراقبته وتخطيطه لمنظومة الفهم لديه. وعرَّف نافز أحمد بقيعى وحنان أحمد هماش (10 ب ب) ما وراء الفهم بأنه قدرة

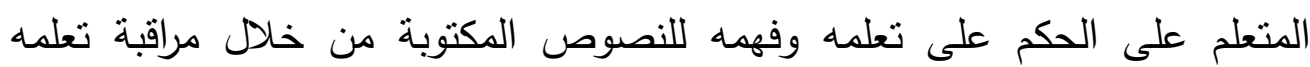
ومراجعة ددى تقدمه أو فثلكه فى استيعاب النصوص واستخدام الإستراتيجيات المناسبة

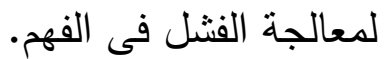

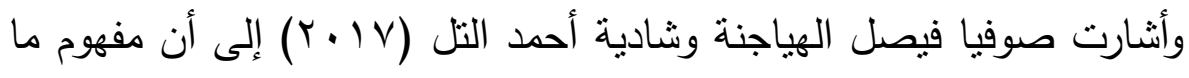

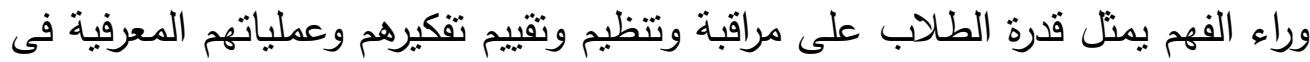

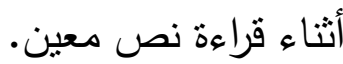
يتضح مما سبق من تعريفات لما وراء الفهم أن القاسم المشترك بينها هو أن ما

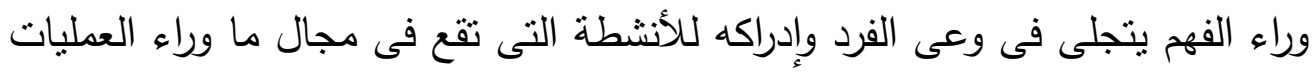
العقلية التتعارف عليها، والتى من شأنها توجيه ومنابعة ورصد وتتظيم وتقييم وإدارة الفهم واستخدام الإستراتيجيات المناسبة لتنظيم ذلك وإدارته. ويمكن تعريف ما وراء الفهم إجرائياً بأنه قدرة المتعلم على الحكم على مدى الإنى

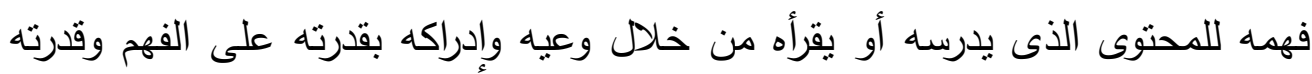

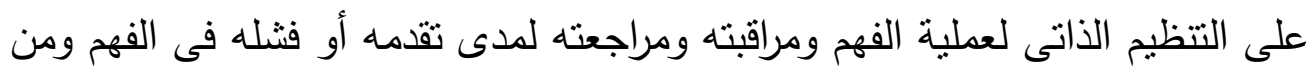
ثم استخدام الإستراتيجيات الملائمة لإدارة ذلك الوعى، ويتحدد بالدرجة الكلية التى لقى

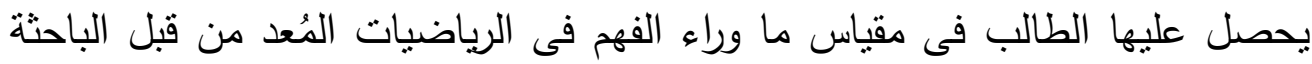
لأغراض هذا البحث منضمناً الابعاد الآتية: 
تقتين مقياس ما وراء الفهم في الرياضيات لدى طلاب الصف الأول الثانوي

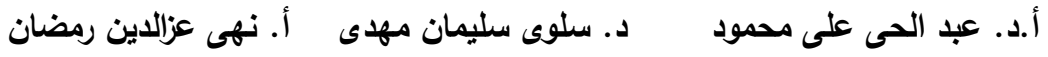

- التظيم: ويعنى نرتيب وإدارة المتعلم للمعلومات وربط الجديد منها بالخلفية

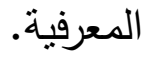

- - التقيم: وهو العملية العقلية التى يستطيع من خلالها المتعلم الحكم على نفسه وعلى أدائه وإستراتيجياته التى يستخدمها فى الفهر.

- الوعى بالقدرة الأتية على الفهم: وبعنى معرفة وإدراك المتعلم لذاته ولعملياته المعرفية ولسعة الفهم لديه.

- الإستراتيجية: وتعنى معرفة وإدراك المتعلم لمدى استخدام الطرق المناسبة

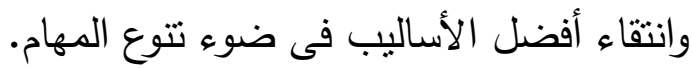

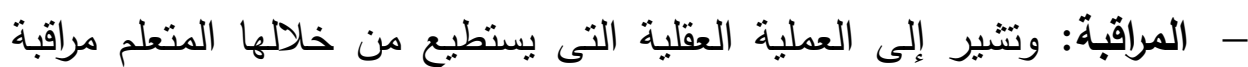
إستراتيجياته التى يستخدمها فى الفهم.

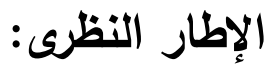

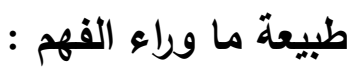

يعد ما وراء الفهم أحد المتغيرات التى انبثقت من ما وراء المعرفة، وهو يتميز ليس فقط بحداثته وإنما أيضاً بأهميته فى الضبط والتحكم فى عمليات الفهر. فقد توصل الباحثّن إلى أن ما وراء الفهم عامل حاسم لحدوث الفهم الجيد، حيث تسمح مهارات ما وراء الفهم للمتعلم برصد عملية الفهم لتوضيح أخطاء الفهم ومن فن وراء (De Beni , Borella, \& Carretti, ثم استخدام الإستراتيجيات العلاجية المناسبة $.2007)$

كما أشنار Hason (2003) \& Marris, Graham \& إلى أن المتعلمين الذين

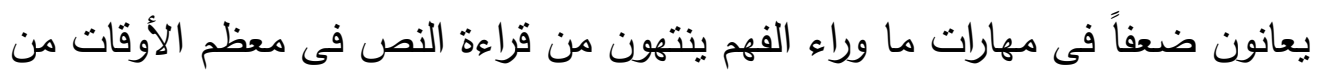
دون فهمه بينما نظرائهر الذين بمتلكون مهارات ما وراء فهم قوية بيتخدمون إستراتيجيات علاجية عند شعورهم بعدم الفهم منل إعادة القراءة أو ربط أجزاء النص أو القيام بتلخيص موجز للموضوع. 
تقتين مقياس ما وراء الفهم في الرياضيات لاى طلاب الصف الأول الثانوي أ.د. عبد الحى على محمود د. سلوى سليمان مهذى أ. نهى عزالدين رمضان

ويتضمن ما وراء الفهم استخدام الإستراتيجيات ما وراء المعرفية للتأكد من تحقيق الأهداف كتقويم مدى الفهم، فالخبرة هنا مسبوقة بنشاط معرفى أى أنه عندما يقرأ الطالب نصًا ولا يستطيع استيعابه يبدأ فى استخدام مهارات ما وراء الفهم، وتتضمن التهن فاعلية ما وراء الفهم وكفاءته فى معرفة المتعلم متى يفهم ومتى لا يفهم وكيف يستخدم الإستراتيجيات العلاجية(Thiede \& Anderson, 2003). وذكر إسماعيل إسماعيل الصاوى (9 . . r) أن الفهم يتضمن جانبين أحدهما معرفى والآخر ما وراء معرفى؛ فالجانب المعرفى للفهم يتمثل فى التظيم والتمييز والاستتناج وإدراك العلاقات وحسن تصور المعنى الحرفى والضمنى للكلمة أو الجملة أو الققرة وذلك خلال فترة زمنية محددة، ويتضمن المكونات الآتية: فهم معانى الكلمات، وفهم معانى الجملة، وفهم معانى الفقرة، وسرعة الفهم؛ أما الجانب الما وراء معرفى للفهم (ما وراء الفهم) يتضمن عمليات عقلية ما وراء معرفية تعتمد على مراقبة الفرد لنفسه والإستراتيجيات التى يستخدمها فى أثناء القراءة وتقييمه لها، ويشمل المكونات الثلاثة الآتية: التخطيط للمهمة، ومراقبة الذات، وتقييم إستراتيجيات الفهم القرائى.

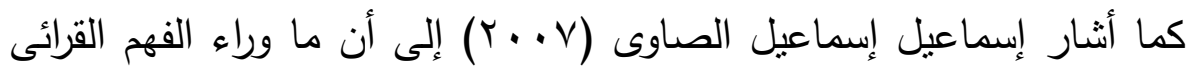
يتضمن عمليات عقلية ما وراء معرفية تقف خلف الفهم القرائى يستخدمها القارئ قبل القراءة وفى أثناءها وبعد الانتهاء منها فى فهم ما يقوم بقراءته؛ فقبل القراءة يقوم القارئ بتحديد الهدف منها وأسبابها والإستراتيجيات التى سيتبعها، وفى أثناء القراءة يترجم تلك وهاء الخطوات إلى سلوك ويراقب استخدامه وتتفيذه لتلك الإستراتيجيات، وبعد الانتهاء من القراءة يقييم فعالية الإستراتيجيات التى استخدمها ويربط بين المعلومات الجديدة والمعلومات المختزنة فى ذاكرته بعيدة المدى كما يشير الأدب النفسى إلى أن ما وراء الفهم القرائى يعتبر حلقة الوصل بين

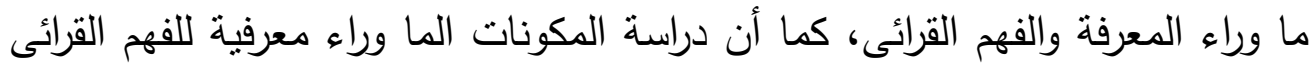
لا تتم بمعزل عن ما وراء المعرفة بوجه عام (إسماعيل إسماعيل الصاوى ،9 . . ب). 
تقتين مقياس ما وراء الفهم في الرياضيات لدى طلاب الصف الأول الثانوي

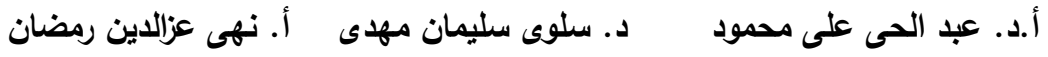

ولقد نُشِرت عديد من البحوث حول أحكام ما وراء الفهم فى منتصف الثمانبنيات، وتم اكتشاف نوعين من دقة ما وراء الفهم وهما: الدقة النسبية والدقة المطلقة.

أولاً: الدقة النسبية Relative accuracy: يتم قياسها عن طريق إيجاد معامل الارنباط بين درجات عينة الطلاب فى اختبارين: اختبار ما وراء الفهم (مثل اختبار Paris,et al.,1984)، واختبار الفهم Nelson Denny Reading منل اختبار نيلسون ودينى لمهارات الفهم القرائىى (NDR))، وتثير الارتباطات الإيجابية العالية إلى أن الطلاب كانوا أكثر دقة فى تمييز النصوص التى تعلموها بشكل جيد من تلك التى تعلموها بشكل أقل جودة Al)

.Ghraibeh, 2014)

ثُانياً: الاقة المطلقة Absolute accuracy

تشير الدقة المطلقة إلى قدرة المتعلم على إصدار الأحكام على تعلمه دون المبالغة أو التقليل من تقدير أدائه على الاختبار مستتداً فى أحكامه على المعرفة السابقة بالموضوع وفاعليته الذاتية، فكلما زادت معرفة المتعلم بالموضوع كانت أحكام التعلم أفضل.(Dunlosky \& Lipko, 2007) ويتم قياس الدقة المطلقة بايجاد معامل الارتباط (جاما) بين درجات الأداء

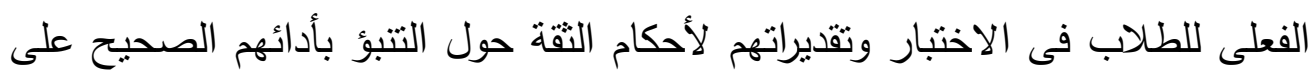

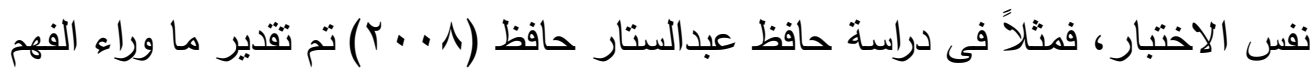
عقب الانتهاء من الإجابة على اختبار الفهم عن طريق وضع المفحوصين تقدير الثقة المتوقعة فى صحة استجاباتهم التى تقابل المفردات بالاختبار على مُنََّل متدرج (من • إلى . . (\%)، وتوصلت النتائج إلى انخفاض فى ما وراء الفهم لدى عينة

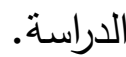

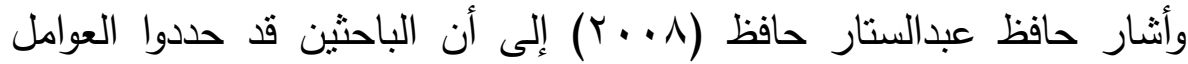
المؤثرة على دقة ما وراء الفهم فيما يلى: 
تقتين مقياس ما وراء الفهم في الرياضيات لدى طلاب الصف الأول الثانوي

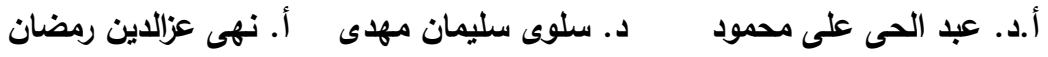

- القدرة القرائية العامة، ومعارف ما وراء المعرفة، وصعوبة النص، ومحاولات القراءة، وطريقة العرض للنصوص المتماسكة.

- خصائص النص، ومعتقدات الأفراد، ومتطلبات المهمة، ونمط القراءة المثمرة، وأحكام يُسر التعلم.

- الألفة بالموضوع وتتشويق النص وتوجهات القارئ الدافعية. - يُسر التجهيز لبنية النصوص ذات التماسك السببى. - الاسترجاع المباشر لمعلومات الفهم القرائى يكون أفضل من الاسترجاع المرجأ وذلك قد يُفسَّر وفقاً لمبدأ الشعور بالمعرفة. - توافر الدلائل أو التلميحات cues عند التجهيز الملائم فى حالة الاسترجاع من بن

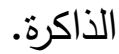
أبعاد ماوراء الفهم:

أنشارت الدراسات التربوبة إلى أن أنشطة ما وراء الفهم تعود فى بدايتها إلى أبحاث ما وراء الذاكرة Metamemory Research؛ فقد حددت أبحاث ما وراء الذاكرة عدة مظاهر لما وراء الذاكرة؛ منها: القلق حول أداء الذاكرة، والثقة فى قدرات

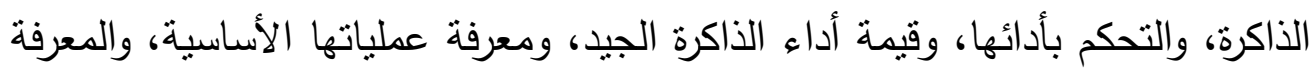

بإستراتيجياتها (Hultsch, Hertzog, Dixon \& Davidson, 1988) Moore, واعتماداً على الأبحاث فى مجال تقييم ما وراء الذاكرة فقد حدد الهداء Zabrucky \& Commander (1997) 1. القلق Anxiety: ويمثل مشاعر التوتر المتعلقة بالفهم القرائى. r. التنظيم Regulation: ويثير إلى الطرق التى يستخدما الفرد لحل مشاكل الفهم. r. المهمة Task: وتتعلق بدرجة معرفة الفرد بعمليات الفهم الأساسية. ء. الإستراتيجية Strategy: وتتعلق بالتقنيات التى يستخدمها الفرد من أجل بله تحسين مستوى الفهم القرائى.

๑. مركز التحكم Control of Locus: ويتطلق بدرجة تحكم الفرد بمهاراته القرائية. 
تقتين مقياس ما وراء الفهم في الرياضيات لدى طلاب الصف الأول الثانوي

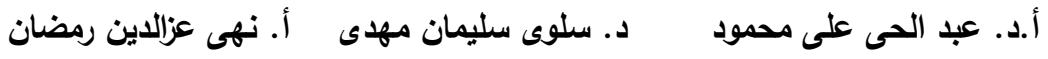

7. القدرة Capacity: وتمنل درجة وعى الفرد بقدرته على الفهم.

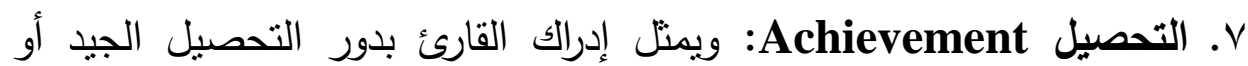
الأداء الجيد فى مهمات الاستيعاب القرائى. وقد حدد (1990) Schmitt أبعاد ما وراء الفهم فى ستة أبعاد وهى:

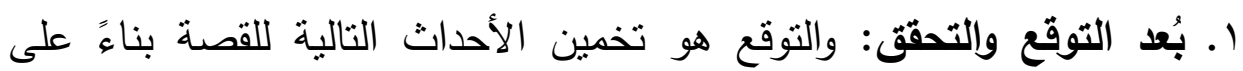
الأحداث السابقة، أما التحقق فهو تأكد القارئ من صحة التونع التوقعات. r. بُعد الاستعراض أو الخصائص السطية: وهو نظرة المتعلم الثاملة للنص، وهى تسهم فى تسهيل الفهم من خلال تتشيط المعلومات العامة والتى تساهم

$$
\text { فى صنع التوقعات. }
$$

r. بُعد تحديد الهُف: وهو تحديد الفرد لهدفه من عملية القراءة. ع. بُعد التساؤل الذاتى: وهو صياغة أسئلة عن القصة. 0. بُعد المعرفة السابقة: وهو تتشيط ودمج المعلومات من الخلفية المعرفية السابقة للقارئ، ويسهم فى عملية الفهم من خلال المساعدة على صنع الاستتناجات،

$$
\text { وتوليد التوقعات. }
$$

7. بُعد تطبيق الإستراتيجيات العلاجية: ويتمثل فى استخدام إحدى الإستراتيجيات عند الشعور بعدم الفهم منل إعادة القراءة. وفى دراسة صفاء ماجد عبد الكريم (11 (Y) تم تحديد سبعة أبعاد لما وراء

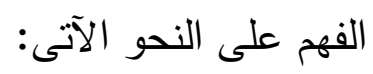

1. المعرفة السابقة: وتعنى كل ما سبق للمتعلم تعلمه من خلال المواقف التعليمية

التى مر بها أو ما ارتبط بحياته من مواقف ولم يتعرض للنشتت أو النسيان. r. القلق: ويعنى استجابة خاصة لحدث ضاغط متعلق بأحد المواقف التعليمية، وقد يكون حالة تختص بموقف واحد، أو سمة تختص بمجموعة من المواقف. 
تقتين مقياس ما وراء الفهم في الرياضيات لاى طلاب الصف الأول الثانوي

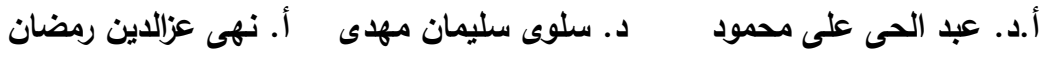

r. التنظيم: ويعنى تحكم المتعلم ذاتياً بعملية التعلم من خلال استخدام إستراتيجيات عدة، كوضع الأهداف، والتخطيط، والمراقبة، والتحكم فى عملية التعلم، وتفعيل العلاقة بين الخبرة الجديدة والخبرة السابقة، والتقييم. ؟. الاهتمام بموضوع النص: ويعنى درجة العناية التى يعطيها المتعلم لموضوع

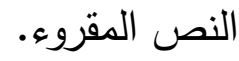
0. الخصائص السطحية للنص: وتعنى ما يتعلق بالثكل الظاهرى للنص دون التوغل فى عمقه وأغواره والتوصل للمعانى الموجودة فيه. 7. التساؤل الأتى فى أثناء معالجة المعلومات: ويعنى البحث عن معلومات جديدة فى النص والتى تعمل على زيادة الاستيعاب عن طريق إثارة أسئلة يسألها الطالب لنفسه فى أنثاء معالجة المعلومات. V. القدرة على التذكر: وتعنى استجابة مكتسبة لمؤثز سابق لها. وأثنارت منال على الخولى(r • r) إلى أن مفهوم ما وراء الفهم بتضمن مكونين هما: 1. المكون المعرفى ويشمل: - الوعى بالذات: وبعنى معرفة وإدراك المتعلم لذاته ولعملياته المعرفية ولسعة

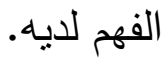
- الوعى بالنص: ويعنى معرفة وإدراك المتعلم لمدى سهولة أو صعوبة النص. - الوعى بالإستراتيجية: ويعنى معرفة وإدراك المتعلم لمدى استخدام الإستراتيجية المناسبة وانتقاء أفضل الإستراتيجيات فى ضوء لإئه نتوع المهام.

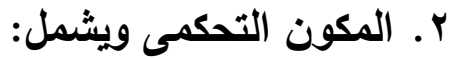
- المراقبة: وتتشير إلى العملية العقلية التى يستطيع من خلالها المتعلم مراقبة إستراتيجياته التى بستخدمها فى الفهم. 
تقتين مقياس ما وراء الفهم في الرياضيات لدى طلاب الصف الأول الثانوي

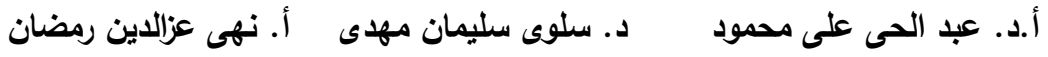

- التخطيط: ويعنى تتظيم المتعلم لعملياته المعرفية وإدارته للمعلومات وربط الجديد منها بالخلفية المعرفية والقلق بشأن الأداء الفعال وتوجيهه لسلوكياته

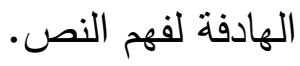
- - التقيم: وهو العملية العقلية التى يسنطيع من خلالها المتعلم الحكم على نفسه وعلى أدائه وإستراتيجياته التى يستخدمها فى فهم النص. النموذج الإجرائى الثلاثى للميتافهم القرائى اقترح إسماعيل إسماعيل الصاوى (V. . . . النموذج الإجرائى الثلاثى للميتافهم Meta-Reading Comprehension Tertiary Operation Model القرائىى فى ضوء الفهر القرائى ونماذج ما وراء المعرفة الثلاثية (MRCTOM) Sternberg, Flavell, J.H.,et al. نموذج)، ونموذج ونموذج (Paris, S.G.,et al) (R. معالجتها من منظور ما وراء معرفى فئ

يتضمن النموذج الإجرائى الثلاثى لما وراء الفهم القرائى ( MRCTOM )

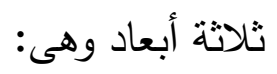
- البُعد الأول: يتعلق بثلاث مراحل ما وراء معرفية لعملية القراءة هى قبل القراءة، وفى أثنائها، وبعد الانتهاء منها. - البُع الثانى: يتعلق بثلاث عمليات ما وراء فهم قرائية هى: التخطيط لمعالم المهمة، ومراقبة الذات، وتقييم إستراتيجيات الفهم القرائى. - البُعد الثالث: يتعلق بمؤشرات للمعالجات الدورية الميتافهم قرائية، من خلاه إستراتيجيات: بناء المعنى المعرفى KWLs، والتساؤل الذاتى، والتلميح بمكان وجود الإجابة (س זم) (إسماعيل إسماعيل الصاوى، 9 . . r). 
تقتين مقياس ما وراء الفهم في الرياضيات لدى طلاب الصف الأول الثانوي

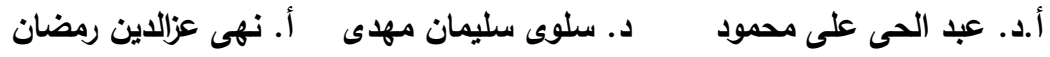

الاراسات السابقة:

دراسة ) (De Beni, Borella, \& Carretti : 2007)

هدفت هذه الدراسة إلى بحث دور الذاكرة العاملة وما وراء الفهم في الفهم القرائى

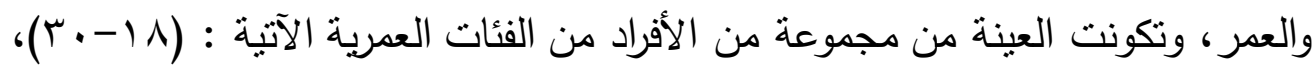

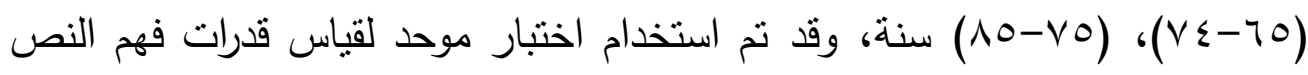
يشتمل على نصين أحدها روائى والآخر تفسيرى، وأثشارت النتائج إلى أن كبار السن

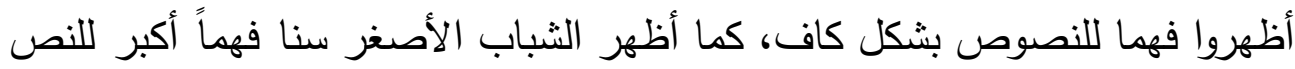

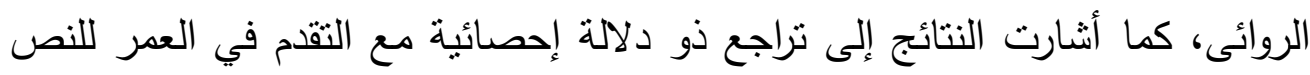
التفسيرى، كما أظهرت نتائج نحليل الإنحدار دور كل من الذاكرة العاملة وما وراء الفهم فى الفهم القرائى للنصوص الروائية والتفسيرية ولم يظهر الدور نفسه مع التقام بالعمر .

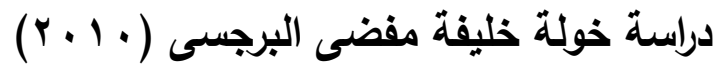
هدفت هذه الدراسة إلى الكثف عن العلاقة بين ما وراء الإستيعاب ودافعية

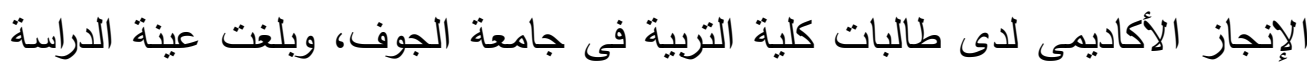

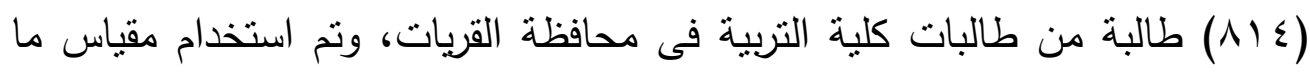
وراء الإنتيعاب من إعداد (Moore, Zabruck, Cammander 1997)، ومقياس دافعية الإنجاز الأكاديمى (إعداد الباحثة)، وأظهرت النتائج: - أن الدرجة الكلية لكل من مقياسى ما وراء الفهم ودافعية الإنجاز كانت مرتفعة. - أن معاملات الإرتباط جميعها بين الدرجات على المقياسين كانت دالة الأهاء

$$
\text { إحصائياً وذات إنجاه إيجابى. }
$$

- وجود فروق ذات دلالة إحصائية بين الدرجات على بُعد المثابرة فى مقياس

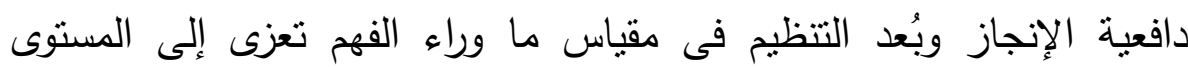

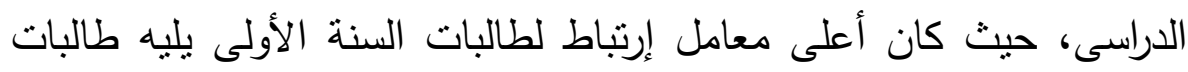

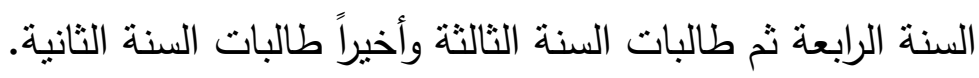


تقتين مقياس ما وراء الفهم في الرياضيات لدى طلاب الصف الأول الثانوي

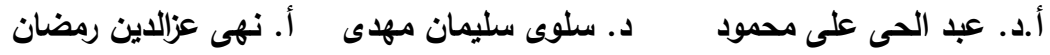

Clark (2012) دراسة

هدفت هذه الدراسة إلى معرفة العلاقة بين الفاعلية الذاتية وما وراء الفهر

القرائى لدى طلبة الصف الرابع والصف الخامس الأساسى بولاية Florida، واستخدم The Reader Self Perception Scale (RSPS) الباحث مقياس الفاعلية الذاتية المُعد من قبل (Henk\&Melnick,1995)، ومقياس ما وراء الفهم المعد من قبل (Schmitt,1990)، وأظهرت النتائج وجود علاقة ذات دلالة إحصائية بين الفاعلية الذاتية العالية واستخدام الطلاب إستراتيجيات ما وراء الاستيعاب.

Al Ghraibeh (2014) دراسة

هدفت هذه الدراسة إلى الكثف عن العلاقة التنبؤية بين الفاعلية الذاتية فى القراءة والعمر وما وراء الفهر بين عدد من الناطقين باللغة العربية من الأجانب، واستخدم الباحث اختبار فاعلية الذات فى القراءة واختبار ما وراء الفهم وتكونت عينة الدراسة من (Tr) طالباً قد تم اختيارهم بطريقة عثوائية من بين الطلاب المسجلين بجامعة الملك سعود، وأظهرت النتائج: - - أن التقدير الاجمالى لاختبار فاعلية الذات الاكاديمية فى القراءة كان مرتفعاً. - أن التقدير الاجمالى لاختبار ما وراء الفهم كان مرتفعاً. - - وجود ارتباط كبير بين المجموع الكلى لاختبار ما وراء الفهم والعمر، حيث كان

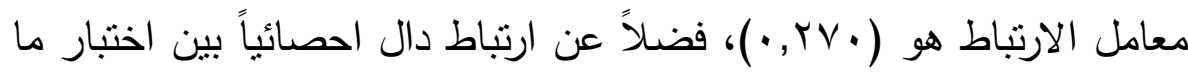
وراء الفهم وفاعلية الذات الاكاديمية حيث كان معامل الارتباط هو (9 0. • ). 
تقتين مقياس ما وراء الفهم في الرياضيات لاى طلاب الصف الأول الثانوي

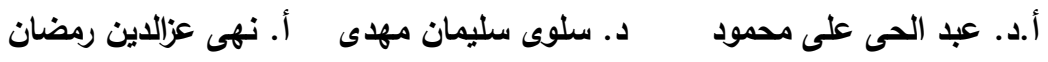

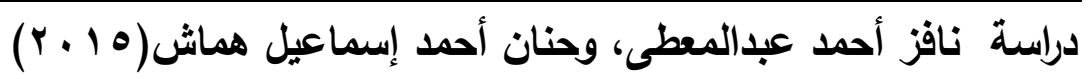
هدفت هذه الدراسة إلى بحث العلاقة بين الفاعلية الذاتية وما وراء الإستيعاب

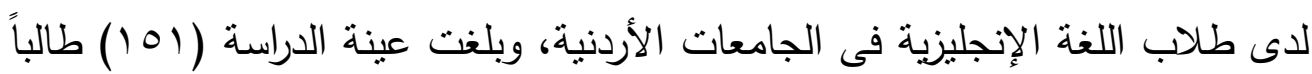
وطالبة من جامعة الإسراء والزيتونة وكلية العلوم التربوية والآداب الجامعية (الأُُروا)، وتم اختيارهم بطريقة عشوائية، واستخدم الباحثان مقياسى ما وراء الإستيعاب لـ لـ Moore, Zabrucky \& Commander ,1997) Mikulecky et al, 1996)، وأظهرت نتائج الدراسة الآتى: - - وجود مستوى متوسط فى الفاعلية الذاتية وما وراء الإستيعاب لدى عينة البحث. - مجود فروق ذات دلالة إحصائية فى الفاعلية الذاتية تبعاً لمتغير المعدل التراكمى ولصالح المعدل الأعلى، وعدم وجود فروق ذات دلالة إحصائية تبعاً لمتغيرى الجنس والمستوى الاراسى. - عدم وجود فروق ذات دلالة إحصائية فى ما وراء الإستيعاب تعزى إلى المستوى الدراسى والمعدل التراكمى والجنس. - مجود علاقة إيجابية دالة إحصائياً بين الفاعلية الذاتية وما وراء الإستيعاب. كما أوصت الدراسة بتتفيذ أنشطة تدريبية خلال مساقات اللغة الإنجليزية تسهم في توظيف مهارات ما وراء الإسنتعاب، وبناء يرامج تدريبية تتمي الفاعلية الذاتية لدى

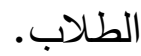

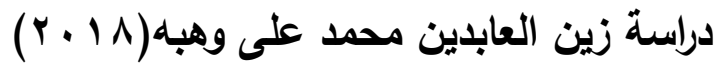

هدفت هذه الدراسة إلى التعرف على طبيعة ماوراء الفهم والكثف عن تشابه أو اختلاف أبعاد ما وراء الفهم فى ضوء بعض المتغيرات الديموجرافية (الفرقة الدراسية -

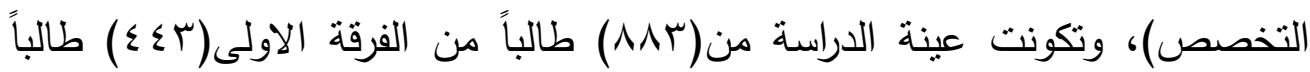
والرابعة (•ع \&) طالباً من الشعب العلمية والادبية بكلية التربية جامعة الأزهر بالقاهرة

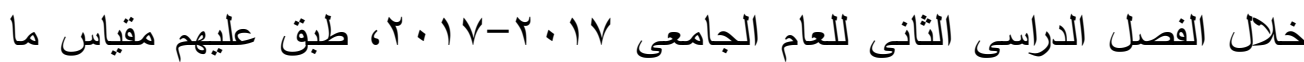
وراء الفهم (إعداد الباحث)، وتم استخدام الأساليب الإحصائية التالية: معامل ارتباط 
تقتين مقياس ما وراء الفهم في الرياضيات لاى طلاب الصف الأول الثانوي

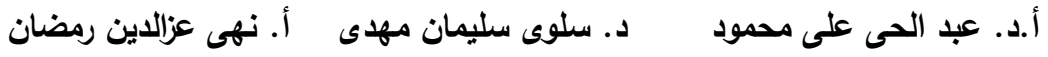

بيرسون، ومعامل ثبات ألفا كرونباخ، والمتوسطات الحسابية، والانحرافات المعيارية،

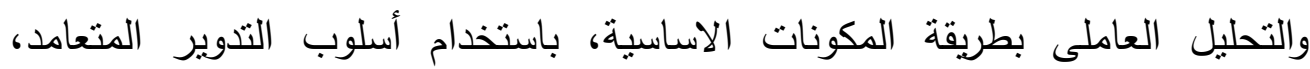

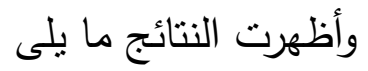
- تختلف البنية العاملية لما وراء الفهم بإختلاف متغير الفرقة الدراسية. - - تختلف البنية العاملية لما وراء الفهم بإختلاف متغير التخصص.

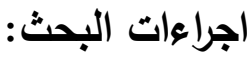

تم اختيار أفراد العينة من بين طلاب الصف الأول الثانوى العام من مدارس بمحافظة أسوان وهم: مدرسة سلوى قبلى الثانوية المشتركة - مدرسة الثهيد أحمد مرعى الثانوية المشتركة- مدرسة محمد صلاح الدين الباقر الثانوية المشتركة - مدرسة توشكى الثانوية المشتركة، حيث بلغ عدد أفراد العينة الاستطلاعية (.بr) طالباً

$$
\text { وطالبةً }
$$
مقياس ما وراء الفهم Metacomprehnsion scale (إعداد الباحثة) :

الهرف من المقياس: يهدف المقياس إلى التعرف على أبعاد ما وراء الفهم (المراقبة، الإستراتيجية، التنظيم) فى مادة الرياضيات لدى طلاب الصف الأول الثانوى العام، ويعبر عن هذه الأبعاد بمجموع استجابات الطلاب على العبارات الموجودة بالمقياس والمرتبطة ببعض المواقف التى تعرض عليهم كمثيرات. خطوات بناء المقياس

فيما يلى عرض الخطوات التى اتبعتها الباحثة فى تصميم هذا المقياس هع بيان أهم معالمها: - n - أُستُمدت بنود هذا المقياس من الإطار النظرى للدراسة والتراث السيكولوجى

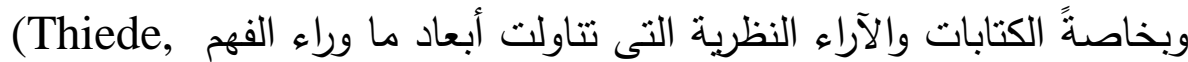


تقتين مقياس ما وراء الفهم في الرياضيات لدى طلاب الصف الأول الثانوي

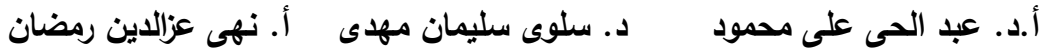

‘(Dunlosky \& Lipko, 2007) ،Anderson \& Therriault, 2003)

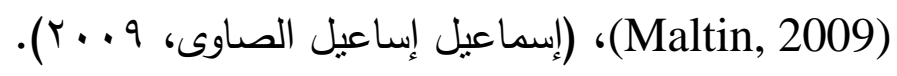

- تم الاطلاع على بعض المقاييس التى اهتمت بقياس ما وراء الفهم، وهذه المقاييس هیى:

Moore, إعداد Metacomprehension scale مقياس ما وراء الفهم Zabrucky\& Commander (1997) عبارة تقيس سبعة أبعاد هى:

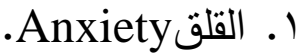
r. Regulation التظيم.

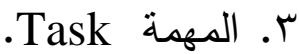
ـ. Strategy الإستراتيجية ه. مركز التحكم Control of Locus. 7. Pchievement التحصيل V. > استبيان إستراتيجيات ما وراء الفهم Metacomprehension Strategy إعداد (1990) Index

$$
\text { ستة أبعاد وهى: }
$$

ا •. Predicting and Verifying التوقع و التحقق r. الاستعراض أو الخصائص السطحية Previewing . r. تحديد الهدف Purpose Setting ع. التساؤل الذاتى Self-questioning.

ه. المعرفة السابقة Drawing from background knowledg. T. التلخيص تطبيق الإستراتيجيات العلاجية Summarizing and applying .fix-up strategies 
تقتين مقياس ما وراء الفهم في الرياضيات لدى طلاب الصف الأول الثانوي

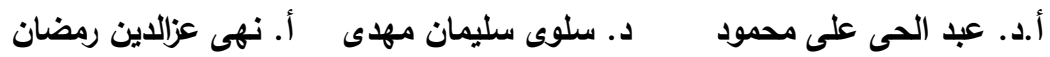

> مقياس التفكير ما وراء المعرفى Awareness إعداد Schraw \& Dennison (1994) Inventory (MAI) المقياس من (Or) عبارة تقيس بعدين وهما:

ا . معرفة المعرفة Knowledg of Cognition.

r. تتظيم المعرفة Regulation of Cognition. وعلى الرغم من اطلاع الباحثة على المقاييس السابقة لقياس ما وراء الفهم ونتشابه البعض منها مع أبعاد الدراسة الحالية، إلا أن الباحثة فضلت إعداد مقياس لما وراء الفهم فى الدراسة الحالية للأسباب الآتية: - بعض المقاييس السابق ذكرها تستخدم مع مراحل دراسية تختلف عن المرحلة الدراسية لعينة الدراسة الحالية (طلاب المرحلة الثانوية). - - هذه المقاييس تم تطبيقها فى بيئة مختلفة عن بيئة الدراسة الحالية. - - بعض المقاييس تحتوى على عدد من العبارات والتى قد لاتكون كافية لإظهار السمة المقاسة، كما أنها لا تتاسب طبيعة الدراسة الحالية.

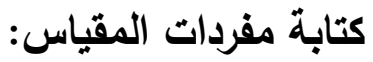
اعتماداً على الخطوتين السابقتين تم صياغة مفردات المقياس باتباع طريقة Likert ا ـ أن تعبر كل مفردة عن فكرة واحدة فقط.

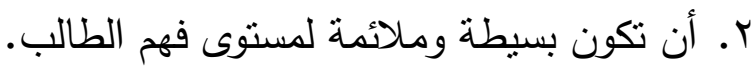
r. أن تكون مرتبطة بالحياة والواقع الذى يعيش فيه الطالب. ـ. أن تكون واضحة ومفهومة ولاتحمل أكثر من معنى. ه. أن تكون العبارات ثقريرية. 
تقتين مقياس ما وراء الفهم في الرياضيات لاى طلاب الصف الأول الثانوي

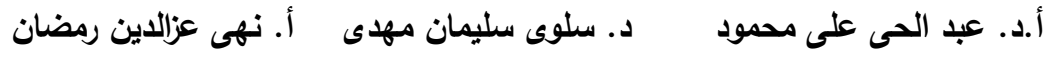

صدق المحكمين:

تم عرض المقياس على مجموعة من المختصين من أساتذة علم النفس عددهم(r ا ) (ملحق( (1)، وطلب منهم إبداء الرأى من حيث: - - وضوح العبارات ودقتها العلمية. - - مناسبة العبارات للبعد الذى تتنمى إليه. - - مناسبة العبارات للمستوى العمرى لأفراد العينة (الصف الأهـ لـأول الثانوى). - - عبارات برون تعديلها أو إضافتها أو حذفها.

وتراوحت نسبة اتفاق السادة المحكمين على عبارات المقياس تراوحت فيما بين

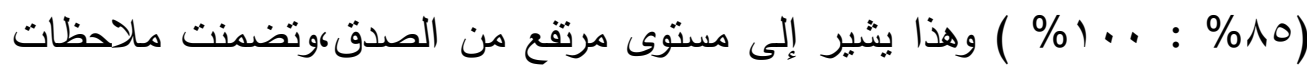

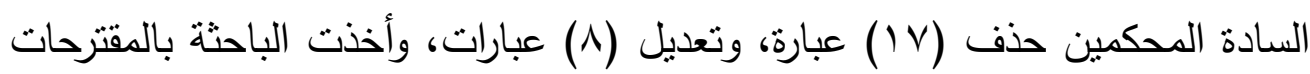
التى قدمها السادة المحكمين وتم تعديل المقياس بناءً على ذلك. الكفاءة السيكومنرية للمقياس: أ- أودق المقياس: تم حساب صدق المقياس باستخدام: - - - صدق التحليل العاملى مابل قبل إجراء التحليل العاملى تم التأكد من صلاحية المصفوفة للتحليل العاملى

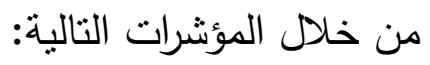

$$
\text { 1- أغلب معاملات الارتباط أكبر من ؟r, •. }
$$

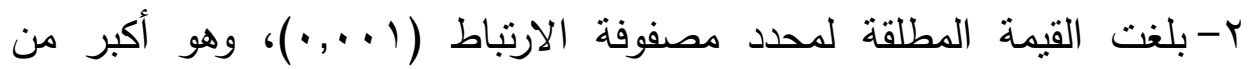

$$
\cdot(\cdot, \cdots)
$$

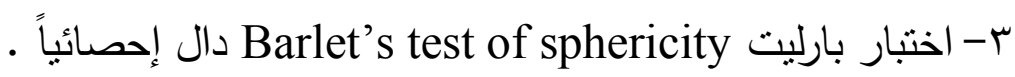
Kaiser-Mayer-Olkn وبلغت قيمة اختبار كايزر - ماير - اولكين $\cdot(\cdot, \mathrm{V}))(\mathrm{KMO})$ 
تقتين مقياس ما وراء الفهم في الرياضيات لدى طلاب الصف الأول الثانوي

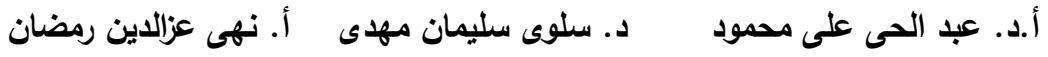

0- مقياس كفاية العينة Measures of Sampling Adequaty (MSA) محصورة ما بين (§ لإجراء التحليل العاملى.

Factor Analysis ومن ثم تم استخدام التحليل العاملى الاستكثافى Exploratory Holding لـ principal components الاوبلمين Direct Oblimin، كما تم اختيار التشبعات الدالة على العوامل المستخلصة وفقاً لما يلى: - العامل الجوهرى هو ما كان له جذر كامن أكبر من الواحد الصحيح. - محك التشبع الجوهرى للعبارة > + r, •، مع الاحتكام للالالة النظرية للعبارات التى تشبعت على أكثر من عامل تشبع دال. - محك اعتماد العامل (r) تشبعات جوهرية على الأقل.(فؤاد أبوحطب وآمال

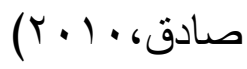
وبناءً على انتقاء العبارات وفقاً لهذه المحكات التثلاثة السابقة فقد تم انتقاء العبارات ذات التشبعات التى تزبد على (r, •)، وكانت النتائج كالآتى: 
تقتين مقياس ما وراء الفهم في الرياضيات لاى طلاب الصف الأول الثانوي

أ.د. عبد الحى على محمود د. سلوى سليمان مهاى أ. نهى عزالدين رمضان

جدول(1) تشبعات مفردات مقياس ما وراء الفهم بالعوامل بعد التذوير وجذورها

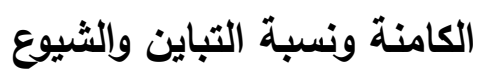

\begin{tabular}{|c|c|c|c|c|c|c|c|c|c|c|c|c|c|}
\hline \multirow{2}{*}{ الشيوعة } & \multicolumn{5}{|c|}{ العـــــــوامـــــــل } & \multirow[b]{2}{*}{ p } & \multirow{2}{*}{ الشيوع } & \multicolumn{5}{|c|}{ العـــــــوامـــــــل } & \\
\hline & الخامس & 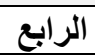 & الثالث & الثانى & الأول & & & الخامس & الرابع & الثالث & الثانى & الالول & $\hat{b}$ \\
\hline (\%१. & & & & & ; $\Sigma N \mid$ & 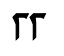 & •Ev7 & & & 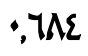 & & & 1 \\
\hline סיז, & & & & & • $[\mathrm{LI}$ & $\Gamma \mu$ & AlA & & & $; \pi$ & & & $\Gamma$ \\
\hline 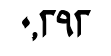 & & & & & • & $\Gamma \varepsilon$ & (EIN & & & & & (29\% & $r$ \\
\hline • & & & & , ०ैq & & ro & (90 & ; & & & & & $\varepsilon$ \\
\hline 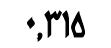 & & , $\% \cdot q$ & ו ו ו, & & & $\Gamma$ & ; ¿£q & & & & & עו & 0 \\
\hline • $\mu \mu$. & & & & & ; & $\Gamma V$ & - (זAr & & & & , ro• & & 7 \\
\hline ( & & $\bullet, \mu \cdot \varepsilon$ & & & 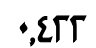 & $\Gamma \Lambda$ & •,19ع & & & & & • • & v \\
\hline • & & & 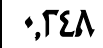 & & & $\Gamma 9$ & , & & & & & • ¿AN & $\Lambda$ \\
\hline ; rll & 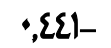 & & & & & $\mu^{*}$ & י (זAI & & & •rv r & & & 9 \\
\hline 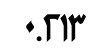 & & •, ¿ूV & & & & $m$ & מזו" & & & & ; reo & & 1. \\
\hline • $\Gamma \cdot 9$ & & & & & • ГцГ & rT & - ז & & & & & 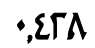 & $\|$ \\
\hline • roL & & ; $\Delta \Delta \Gamma$ & & & & $\mu r$ & 西 & & & י $17 \pi$ & & & $\pi$ \\
\hline •,乏O乏 & & • ТV & & & & $r \varepsilon$ & (ז9" & & & & & ; $\Delta \Delta \mathrm{H}^{\mu}$ & $\pi$ \\
\hline •,2\|l & & ;.7.5 & & & & ro & •, Гع০ & & & & & (199 & $1 \varepsilon$ \\
\hline 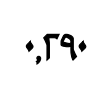 & & & & $\begin{array}{c}- \\
\text { ז זAT }\end{array}$ & & ry & ; ¿q॰ & & & & 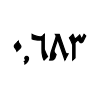 & & 10 \\
\hline (99 & & & • & & & $r v$ & 汇厂 & : $\Sigma \varepsilon \cdot-$ & & & & (ro9 & 17 \\
\hline 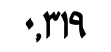 & 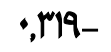 & & (M77 & & & ra & (rrq & 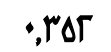 & & & •, 217 & & IN \\
\hline י,Г人7 & & (riv & & & & rq & 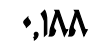 & & & & & יזVV & in \\
\hline 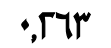 & & ב lny & & & & $\varepsilon$ & גרזי & & & & & (ro9 & 19 \\
\hline 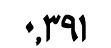 & & & & & •, $\Delta \cdot \varepsilon$ & घ) & 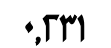 & & & & • & & $\Gamma \cdot$ \\
\hline & & & & & & & ; $\mu^{\top}$ & & & & & 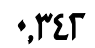 & $\Pi$ \\
\hline & $1,01 \Lambda$ & $1,7 v 9$ & I, V9ז & $\Gamma, 129$ & 0,991 & \multicolumn{8}{|c|}{ 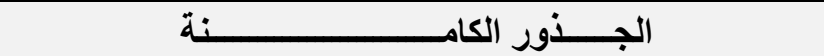 } \\
\hline & $r, v \cdot r$ & $\varepsilon, 90$ & $\varepsilon, \mathrm{rVT}$ & $0, \Gamma \varepsilon \mid$ & $1 \varepsilon, 71 \%$ & \multicolumn{8}{|c|}{ نــــبة التباين العــــــــــلى } \\
\hline & \multicolumn{5}{|c|}{$\mu \Gamma, \Gamma \varepsilon$} & \multicolumn{8}{|c|}{ نـسـبة التباين المجمع } \\
\hline
\end{tabular}


تقتين مقياس ما وراء الفهم في الرياضيات لدى طلاب الصف الأول الثانوي

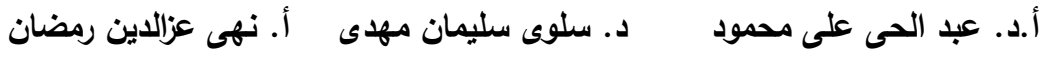

يتضح من الجدول السابق أن عدد العبارات المستخلصة (ب٪) عبارة موزعة على

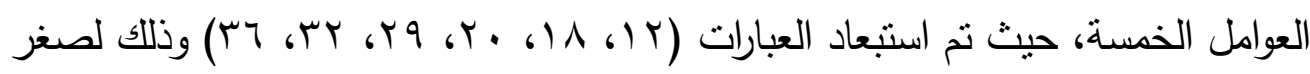

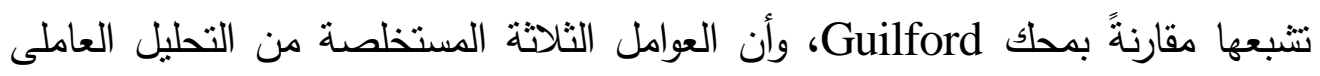
استوعبت نباين بمقدار ( ع . , rr\%) من التباين الكلى لمتغيرات المصفوفة. ويمكن استخلاص العوامل التالية:

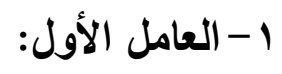

الجذر الكامن لهذا العامل أعلى من الواحد الصحيح حيث بلغ (1) (1) (1) وبسهم بنسبة (T/7,乏) (1\%) من التباين الكلى للمقياس، كما بلغ عدد البنود المتشبعة

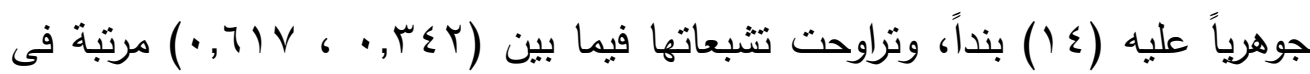
الجدول التالى طبقاً لقيم تشبعاتها بالعامل.

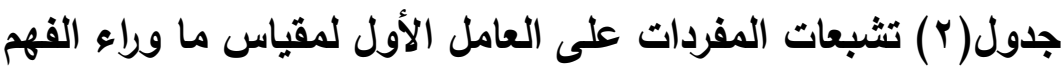

\begin{tabular}{|c|c|c|}
\hline التشبعات & 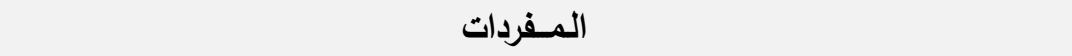 & b \\
\hline$\cdot, \mathrm{TIV}$ & أحافظ على تسلسل خطوات حل أى مسألة رياضية. & $\Delta$ \\
\hline$\cdot \Delta \Delta r$ & أسأل نفسى بإستمرار إذا كنت أتبع الخطوات الصحيحة للحل. & ir \\
\hline$\cdot, \Delta \Gamma \varepsilon$ & أعيد كتابة خطوات حل المسألة الرياضية عندما يصعب حلها. & $\Gamma V$ \\
\hline$\cdot, \Delta \cdot \varepsilon$ & أقرأ المسائل الرياضية الصعبة بتأنٍ حتى أستطيع فهمها. & $\varepsilon 1$ \\
\hline$\cdot, \Sigma q \mu$ & أنظم أفكارى لحل مسألة رياضية بثكل متسلسل. & $\mu$ \\
\hline • $\Sigma \wedge V$ & أعيد تنظيم خطوات الحل عند ظهور صعويات فى حل مسألة رياضية & $\Lambda$ \\
\hline ; $[\Lambda I$ & أرتب المعطيات بطريقة منظمة قبل تنفيذ الحل. & $\Gamma r$ \\
\hline 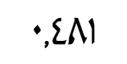 & أعيد صياغة المسألة بالطريقة التى تسهل فهمها. & $\Gamma \Gamma$ \\
\hline •,¿ГА & أتاكد من فهمى لمحتوى المسألة قبل حلها. & 11 \\
\hline , r99 & أتحقق من وصولى للإجابة الصحيحة عند حل المسائل الرياضية & $1 \varepsilon$ \\
\hline 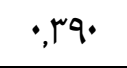 & أتبع الخطة التى وضعتها لحل مسألة رياضية معينة. & $v$ \\
\hline , rVז & أتصور خطة لخطوات الحل فى ذهنى قبل تنفيذه. & $\Gamma \varepsilon$ \\
\hline 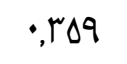 & أقوم بتقدير مدى فائدة الطريقة التى أستخدمها أثناء قيامى بحل المسائل الرياضية. & 19 \\
\hline$\cdot, r \varepsilon \Gamma$ & أستطيع الحكم على مدى فهمى للارس بعد استذكاره. & $\Gamma$ \\
\hline
\end{tabular}


تقتين مقياس ما وراء الفهم في الرياضيات لاى طلاب الصف الأول الثانوي

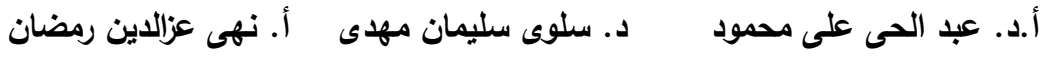

ويلاحظ من محتوى البنود المشبعة على هذا العامل أن معظمها يدور حول

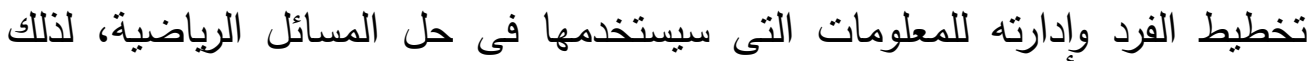
يمكن تسمية هذا العامل بـ "التنظيم".

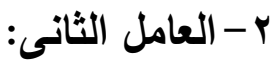

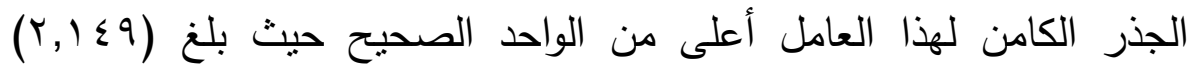

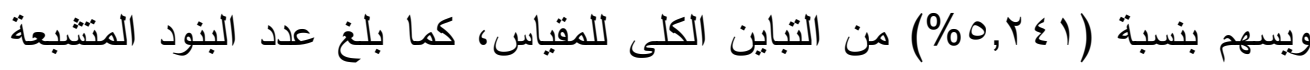

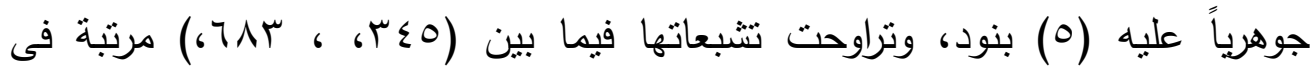
الجدول التالى طبقاً لقيم تشبعاتها بالعامل. جدول (r) تثبعات المفردات على العامل الثانى لمقياس ما وراء الفهم

\begin{tabular}{|c|c|c|}
\hline التشبعات & المــردات & r \\
\hline , ThN & أقيم طريقة حلى للمسائل الرياضية بكتابة إيجابياتها وسلبياتها. & 10 \\
\hline , OVq & أقوم بتقسيم الوقت على كل خطوة من خطوات الحل. & Го \\
\hline ,217 & أقدر لنفسى الدرجة التى أستحقها بعد حل أى مسألة رياضية. & IN \\
\hline r ro & ألتزم بالوقت المحدد لحل أى مسألكة رياضية. & 7 \\
\hline , rEO & أراجع إجاباتى بعد كل خطوة من خطوات الحل. & $1 \cdot$ \\
\hline
\end{tabular}

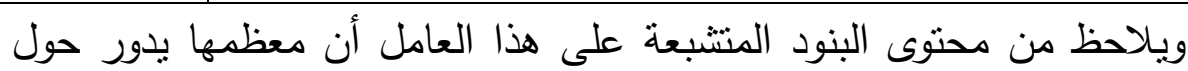

تحديد الفرد لمدى فاعلية الطرق التى يتبعها للوصول للحل ، لذلك يمكن تسمية هذا

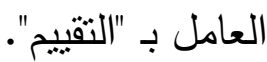

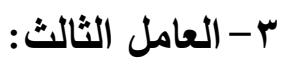

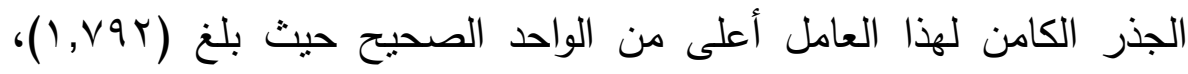

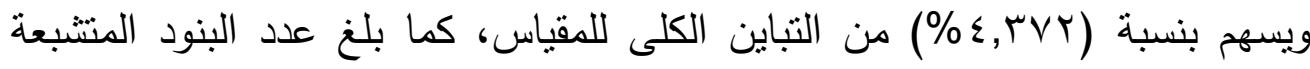

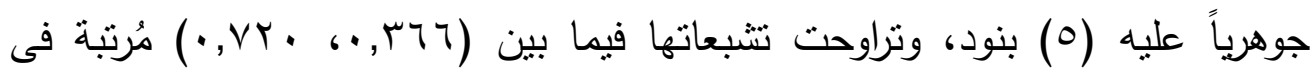
الجدول التالى طبقاً لقيم تشبعاتها بالعامل.

جدول (ء) تشبعات المفردات على العامل الثالث لمقياس ما وراء الفهم

\begin{tabular}{|c|c|c|}
\hline التشبعات & المـفردات & b \\
\hline$\cdot \mathrm{V \Gamma} \cdot$ & أجيد فهم المسائل الرياضية. & $\Gamma$ \\
\hline ,T^E & يمكننى فهم أى مسألة رياضية. & 1 \\
\hline ; $07 \mathrm{~V}$ & أستطيع استتتاج العلاقات اللازمة لحل المسائل الرياضية. & rV \\
\hline
\end{tabular}


تقتين مقياس ما وراء الفهم في الرياضيات لاى طلاب الصف الأول الثانوي

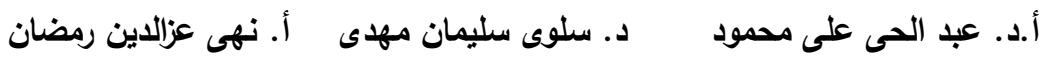

\begin{tabular}{|c|c|c|}
\hline , rVr & مسألجة جديدة مشا أقع فيه من أخطاء فى حل مسائل رياضية سابقة عند حل & 9 \\
\hline ; r77 & أجيد فهم الألغاز الرياضية. & $r \Lambda$ \\
\hline
\end{tabular}

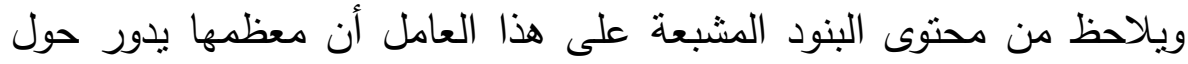

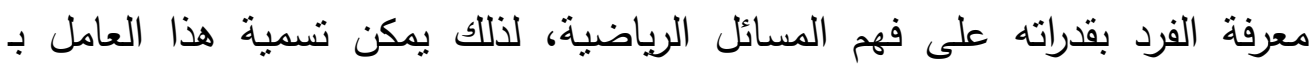
"الوعى بالقدرة الذاتية على الفهر".

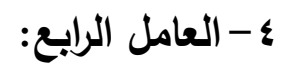

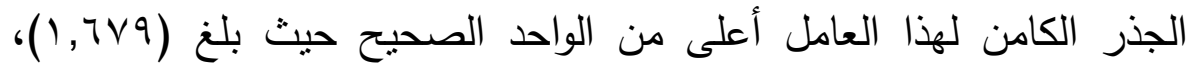

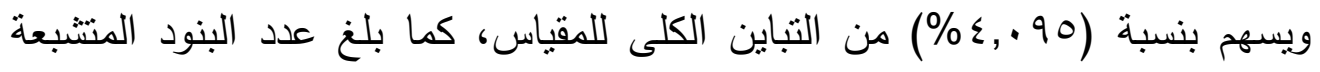

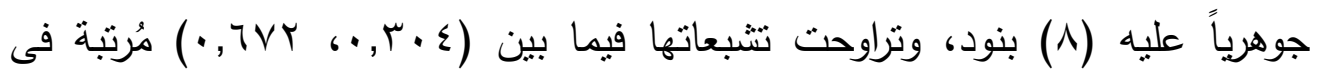

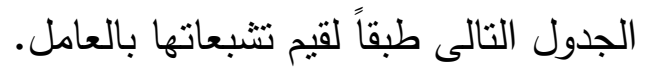

جدول (•) تشبعات المفردات على العامل الرابع لمقياس ما وراء الفهم

\begin{tabular}{|c|c|c|}
\hline 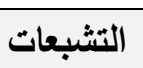 & المــفردات & م م \\
\hline$\cdot$ • IVז & أحاول عمل علاقات بين الأفكار فى كتابى الدراسى. & $r \varepsilon$ \\
\hline$\cdot 7 \cdot \Gamma$ & أحاول عمل علاقات بين الأفكار فى كتابى الاراسى ويين المطومات التى تعمتها من قبل. & $r \Delta$ \\
\hline$; \Delta \Delta \Gamma$ & بعد دراستى أضع ملخصاً لما قت باستذكاره. ب & $\mu \mu$ \\
\hline , ¿乏V & أقوم بفحص المسائل الرياضية للتمييز بين المسائل الرياضية الصعبة والسهلة. & rl \\
\hline : rry & أحدد ما أعرفه وما لا أعرفه فى المسألة الرياضية. & $\varepsilon$. \\
\hline , riv & أدرك نقاط القوة والضعف فى قدراتى المتعلقة بالرياضيات. & rq \\
\hline , r.q & أقوم بتوليد أفكار بديلة لمواجهة صعويات حل المسائل الرياضية. & $\Gamma 7$ \\
\hline , r॰c & أراجع المعلومات التى تساعدنى على حل مسألة رياضية & $\Gamma \Lambda$ \\
\hline
\end{tabular}

ويلاحظ من محتوى البنود المشبعة على هذا العامل أن معظمها لئه ربافيه يدور حول

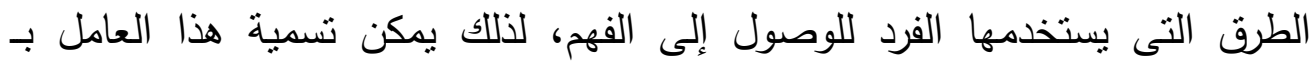

$$
\text { "الإستراتيجية". }
$$

الجذر الكامن لهذا العامل أعلى من الواحد الصحيح حيث بلغ (1) (1) 1)،

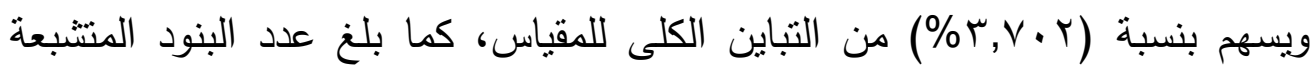

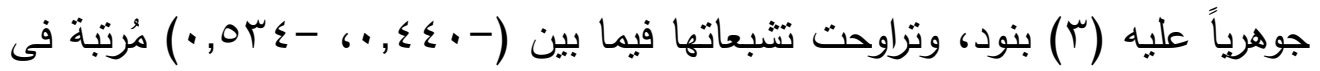
الجدول التالى طبقاً لقيم تشبعاتها بالعامل. 
تقتين مقياس ما وراء الفهم في الرياضيات لاى طلاب الصف الأول الثانوي أ.د. عبد الحى على محمود د. سلوى سليمان مهذى أ. نهى عزالدين رمضان

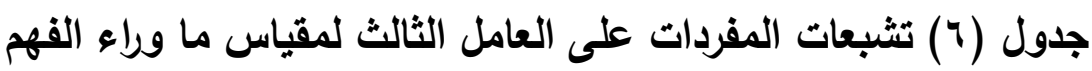

\begin{tabular}{|c|c|c|}
\hline التشبعات & المـفردات & م \\
\hline$; \Delta \varepsilon_{-}$ & أتحدث بصوت مسموع مع نفسى عند حل مسألة رياضية. & $\varepsilon$ \\
\hline 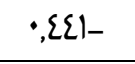 & أستخدم عدة طرق لحل المسائل الرياضية الصعبة. & $\mu^{\prime}$ \\
\hline$\cdot \sum \varepsilon \cdot-$ & أعيد حل المسائل الرياضية بأكثر من طريقة لمقارنة النتائج والتحقق من صحتها. & 17 \\
\hline
\end{tabular}

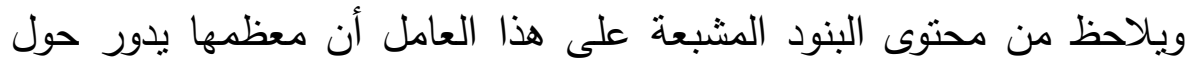
متابعة الفرد لإستراتيجياته التى يستخدمها فى فهم المسائل الرياضية، لذلك يمكن تسمية

$$
\text { هذا العامل بـ "المراقبة". }
$$

ب-ثبات مقياس ما وراء الفهم:

تم حساب معاملات ثبات أبعاد مقياس ما وراء الفهر عن طريق حساب

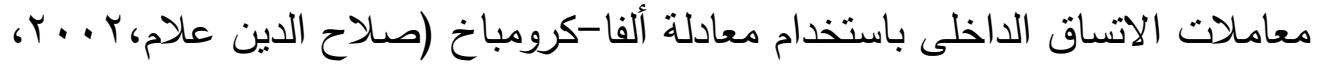
صع (Y))، والجدول التالى يوضح معاملات ثبات أبعاد مقياس ما وراء الفهم باستخدام معامل ألفا-كرومباخ. جدول (V) معاملات ثبات الأبعاد الفرعية لمقياس ما وراء الفهم باستخدام معامل ألفا $(17.0)$

\begin{tabular}{|c|c|c|}
\hline معامل الثبات & عدد العبارات & الأبعاد \\
\hline$\cdot, \vee \wedge$. & $1 \leq$ & التظظيم \\
\hline$\cdot, 0 . \leq$ & 0 & التقييم \\
\hline., $07 \mathrm{~V}$ & 0 & الوعى بالقدرة الذاتية على الفهم \\
\hline$\cdot, 091$ & $\wedge$ & الاستراتيجية \\
\hline$\cdot, \sum Y_{1}$ & $r$ & المراقبة \\
\hline
\end{tabular}

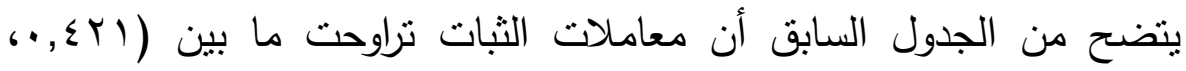
. VA .

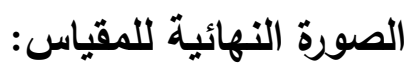

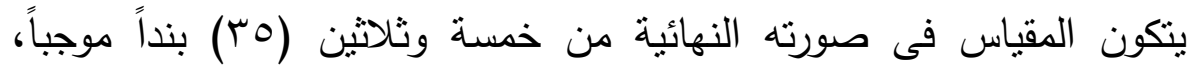
وتتوزع البنود على الأبعاد الخمسة للمقياس كما يتضح من الجدول التالى: 
تقتين مقياس ما وراء الفهم في الرياضيات لاى طلاب الصف الأول الثانوي

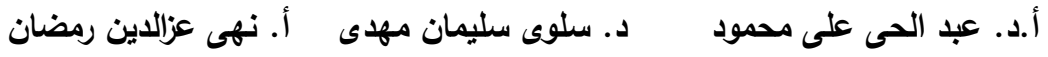

جدول (^) توزيع بنود مقياس ما وراء الفهم على الأبعاد الثلاثة

\begin{tabular}{|c|c|c|c|c|}
\hline النئوية & فى كلد البنود & أرقام البنود فى كل عبارة & 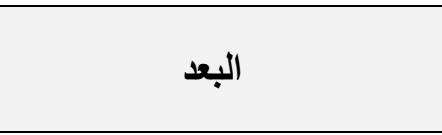 & r \\
\hline$\varepsilon \cdot$ & $1 \varepsilon$ & 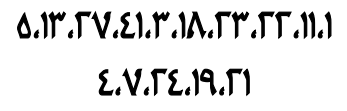 & 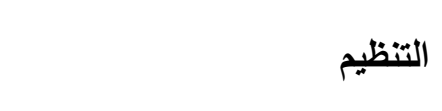 & 1 \\
\hline $1 \varepsilon, \Gamma 9$ & $\Delta$ & $10.50 .1 \mathrm{~V} .7 .1 \%$ & التقييم & $\Gamma$ \\
\hline $12, \Gamma 9$ & $\Delta$ & ra.r.l.rv. & الوعى بالقدرة الذاتية على الفهم & $r$ \\
\hline$\Gamma \Gamma, \Lambda T$ & $\Lambda$ & 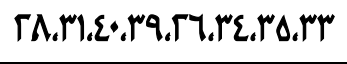 & الاستراتيجية & $\varepsilon$ \\
\hline$\Lambda, \Delta V$ & $r$ & $\varepsilon . r_{0}, 17$ & المراقبة & $\Delta$ \\
\hline$\%$ & ro & \multicolumn{3}{|c|}{ المقياس ككل } \\
\hline
\end{tabular}

يتم تصحيح المقياس طبقاً لطريقة ليكرت Likert، بحيث يختار الطالب بديل

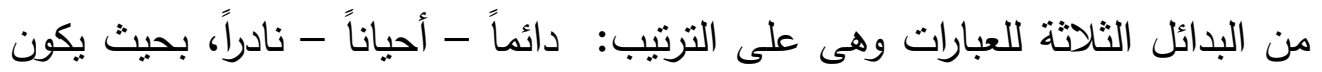

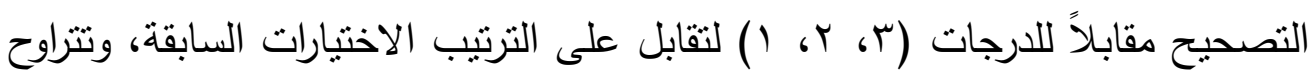

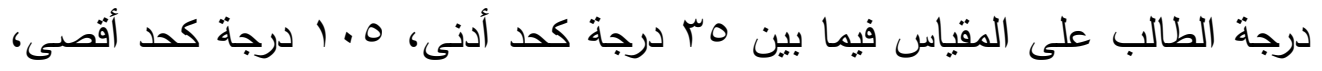
وبالتالى فإن الدرجة الكلية فى المقياس تساوى مجموع درجات الطالب فى أبعاد المقياس الخمسة، وتتير الدرجة المرتفعة فى المقياس إلى تمتع الطالب بما وراء فهم مرتفع (ملحق (r)). 
تقتين مقياس ما وراء الفهم في الرياضيات لاى طلاب الصف الأول الثانوي

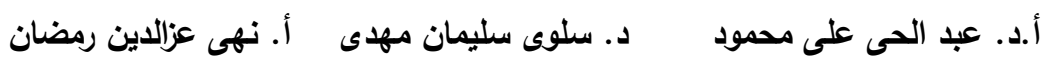

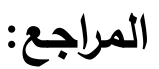

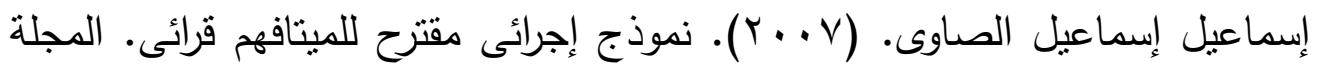

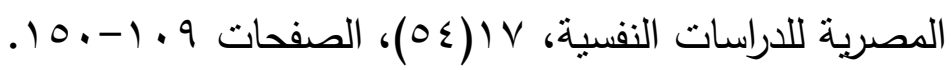

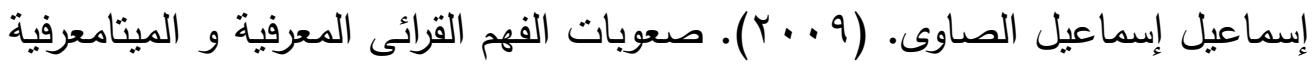

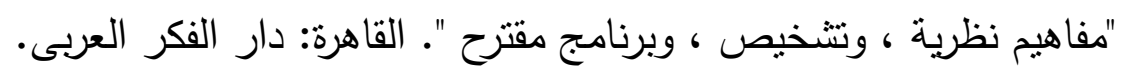

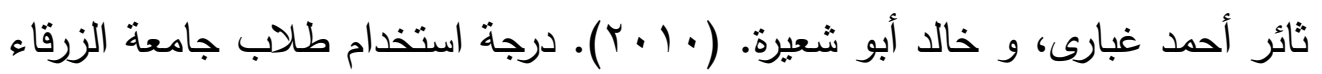

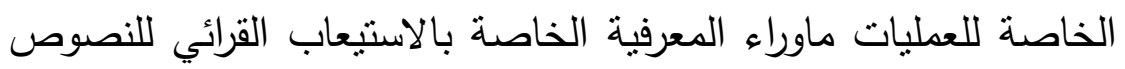
الاجنيبة في ضوء بعض المتغيرات. دراسات العلوم التربوية -الاردن، (ل)

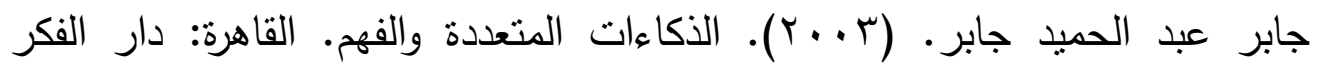

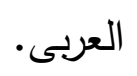

حافظ عبد الستار حافظ. (سبتمبر ، 1 + . ץ). أثر نوع بروفيل التفكير ومتغيرى التحديث

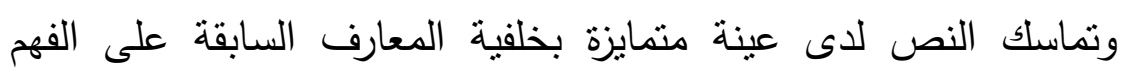

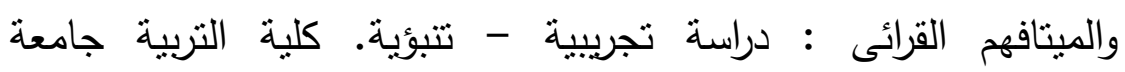

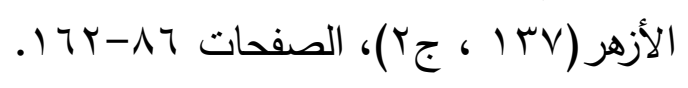

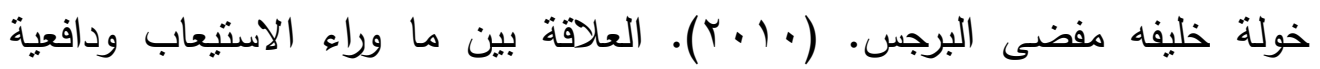

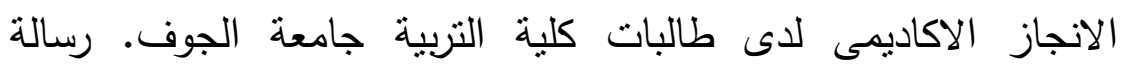

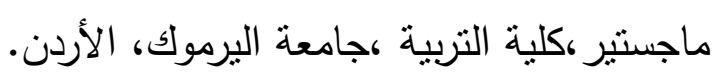

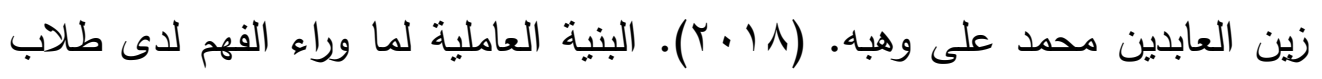

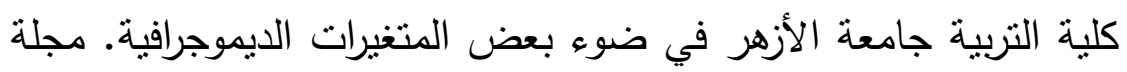

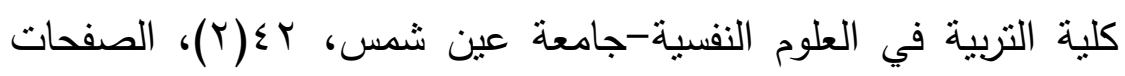

$$
\text { .r. } 1 .-1 r r
$$

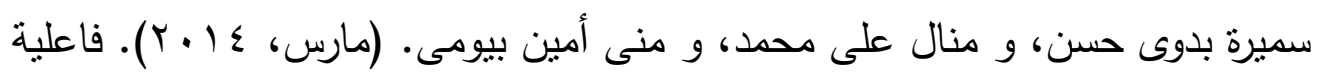

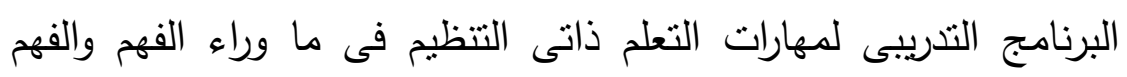

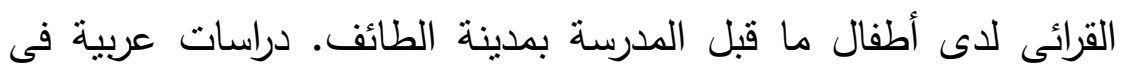

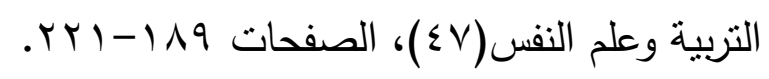


تقتين مقياس ما وراء الفهم في الرياضيات لاى طلاب الصف الأول الثانوي

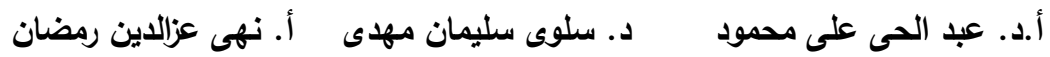

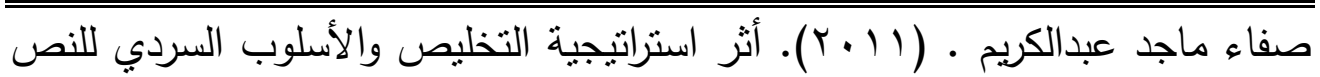

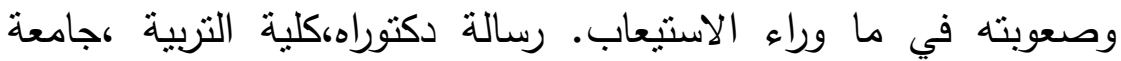

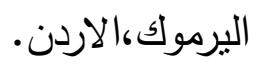

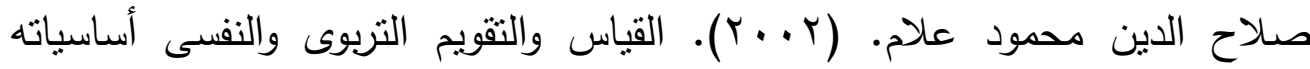
وتطبيقاته وتوجهاته المعاصرة. القاهرة: دار الفكر العربى.

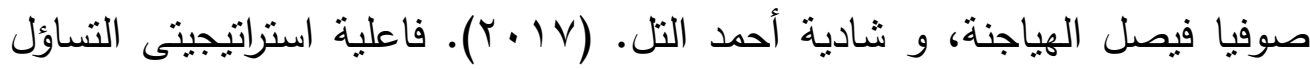
الذاتى و تتال القمر فى تتمية الاستيعاب القرائى وما وراء الاستيعاب إنهابه

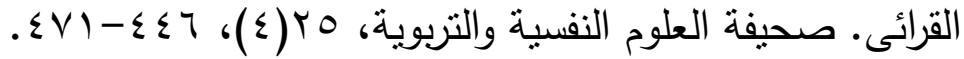

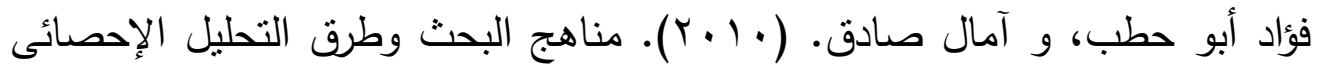
فى العلوم النفسية والتربوية والاجتماعية. القاهرة: مكتبة الانجلو المصرية.

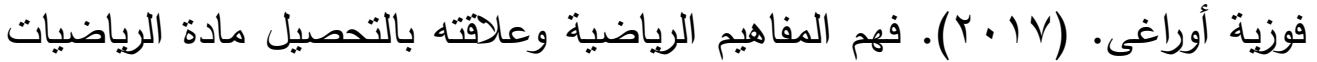

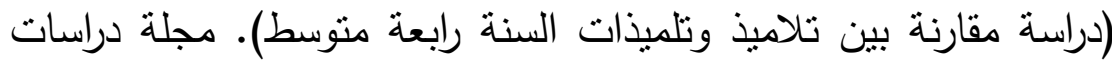

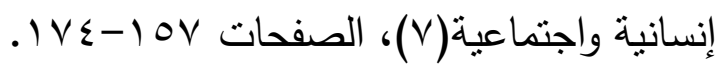

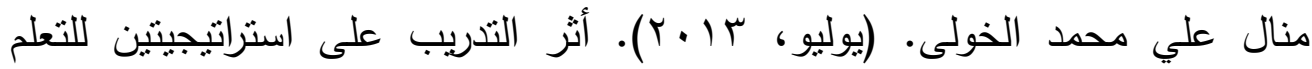

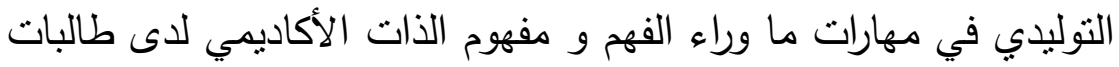
الصف الثاني المتوسط ذوات صعوبات الفهم القرائي بالمملكة العربية

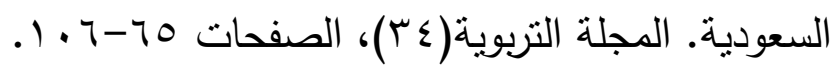

نافز أحمد بقيعى، و حنان أحمد هماش. (سبتمبر ، 10 ـ ب). الفاعلية الذاتية وعلاقتها بما وراء الاستيعاب لدى عينة من طلبة اللغة الإنجليزية في الجامعات

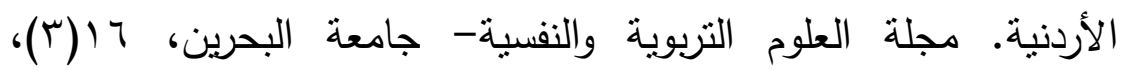

$$
\text { الصفحات الصن }
$$

نوال محمد عبدالرحمن الراجح. (10 ب ب). مستوى حل المشكلات الرياضية لدى طالبات جامعة الأميرة نوره بنت عبدالرحمن. المجلة الدولية التربوية

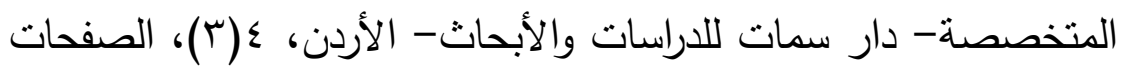




\section{تقتين مقياس ما وراء الفهم في الرياضيات لدى طلاب الصف الأول الثانوي \\ أ.د. عبد الحى على محمود د. سلوى سليمان مهذى أ. نهى عزالدين رمضان}

Afflerbach, P. P., Pearson, D., \& Paris, S. G. (2008). Clarifying Differences Between Reading Skills and Reading Strategies. The Reading Teacher, 61(5), pp. 364- 373.

Al Ghraibeh, A. M. (2014). Academic Self-Efficacy in Reading as a Predictor of Metacomprehension among Arabic Nonnative Speakers. International Journal of Applied Psychology, 4(1), 1-12.

Clark, P. I. (2010). Examining the relationship between selfefficacy and metacomprehension strategy usage in forth and fifth grade students in reading. Un dissertation publishing,Regent University.

De Beni , R., Borella, E., \& Carretti, B. (2007). Reading Comprehension in Aging: The Role of Working Memory and Metacomprehension. Aging, Neuropsychology, and Cognition, 14, 189-212.

Dunlosky, J., \& Lipko, A. (2007, Aug.). Metacomprehension A Brief History and How to Improve Its Accuracy. Current Directions in Psychological Science, 16, 228-232.

Harris, K., Graham, S., \& Mason, L. (2003). Self-regulated strategy development in the classroom: Part of a balanced approach to writing instruction for students with disabilities. Focus on Exceptional Children, 35(7), $1-16$.

Hultsch, D. F., Hertzog, C., Dixon, R. A., \& Davidson, H. (1988). Memory Self-Knowledge and Self-Efficacy in the Aged. In M. H. C.J.Brainerd, Cognitive Development in Adulthood (pp. 65-92). Verlag New York: Springer.

Kern, D. E. (2003). The Relationships Between Metacomprehension Strategy Awareness ,Student Reading Performance And Comprehension Strategy 
تقتين مقياس ما وراء الفهم في الرياضيات لاى طلاب الصف الأول الثانوي

أ.د. عبد الحى على محمود د. سلوى سليمان مهاى أ. نهى عزالدين رمضان

Instruction. A Dissertation Of Doctor. University Of Rhode Island.

Lin, L., Moore, D., \& Zabrucky, K. (2000). Metacomprehension knowledge and comprehension expository and narrative texts among younger and older adults. Educational Gerontology, 26, pp. 737-749.

Linderholm, T., Zhao, Q., Therriault, D., \& Cordell-McNulty, K. (2008). Metacomprehension effects situated within an anchoring and adjustment framework. Metacognition Learning, 3, 175-188.

Maltin, M. W. (2009). Cognitive Psychology. Asia: John Wiley\& Sons.

Moore, D., Zabrucky, K., \& Commander, C. (1997). Validation of the metcomprehension scale. Contemporary Educational Psychology, 22, pp. 457-471.

Rawson, K., Dunlosky, J., \& McDonald, S. L. (2002). Influences of metamemory on performance predictions for text. Quarterly Journal of Experimental Psychology, 55(2), 505-524.

Rittle-Johnson, B., Siegler, R. S., \& Alibali, M. W. (2001). Developing Conceptual Understanding and Procedural Skill in Mathematics: An Iterative Process. Journal of Educational Psychology, 93(2), 346- 462.

Schmitt, M. C. (1990, March). A Questionnaire to Measure Children's Awareness of Strategic Reading Processes. The Reading Teacher, 43(7), pp. 454-461.

Schraw, G., \& Dennison, R. S. (1994). Assessing Metacognitive Awareness. Contemporary Educational Psychology, 19, pp. 460-475. 
تقتين مقياس ما وراء الفهم في الرياضيات لدى طلاب الصف الأول الثانوي

أ.د. عبد الحى على محمود د. سلوى سليمان مهذى أ. نهى عزالدين رمضان

Thiede, K. W., \& Anderson, M. C. (2003). Summarizing can improve metacomprehension accuracy. Contemporary Educational Psychology(28), 129-160.

Thiede, K. W., Anderson, M. C., \& Therriault, D. (2003). Accuracy of Metacognitive Monitoring Affects Learning of Texts. Journal of Educational Psychology, $95,66-73$.

York, C. (2006). An Exploration of the Relationship between Metacomprhension Strategy Awareness and Reading Comprehension Performance with Narrative and Science Texts. Unpublished Doctoral dissertation,University of Southern Mississippi,U.S.A.

Zhao, Q., \& Linderholm, T. (2008). Adult Metacomprehension: Judgment Processes and Accuracy Constraints. Educ Psychol Rev, 20, 191-206. 
تقتين مقياس ما وراء الفهم في الرياضيات لاى طلاب الصف الأول الثانوي

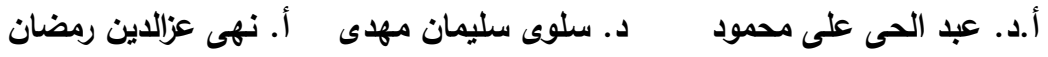

ملحق(1)

قائمة أسماء السادة محكمي مقياس ما وراء الفهم

\begin{tabular}{|c|c|c|}
\hline الوظيفة & 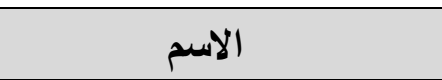 & p \\
\hline - جامعة القاذه أنفس التريوى بكلية الاراسات العليا للتربية بالقاهرة & أ.د/ أمين على محمد سليمان & 1 \\
\hline أستاذ الصحة النفسية بكلية التربية بالمنيا - جامعة المنيا & أ.د/ سيد عبدالعظيم محمد & r \\
\hline 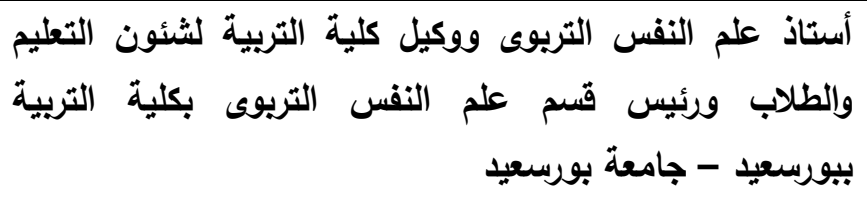 & أ.د/ شيرين محمد أحمد دسوقى & $r$ \\
\hline أستاذ علم النفس التريوى بكلية التربية بقتا - جامعة جنوب & حسن أ.د محسوب عبدالقادر الضوى & $\varepsilon$ \\
\hline أستاذ علم النفس التريوى بكلية التربية بقتا - جامعة جنوب & أ.د/ عصام على الطيب & 0 \\
\hline أسوان أصحة النفسية المساعد بكلية التربية بأسوان - جامعة & د/ عادل محمد الصادق & 7 \\
\hline أستاذ علم النفس التريوى المساعد بكلية التربية بالمنيا - & د/ محمد كامل عبدالموجود & v \\
\hline مدرس علم النفس التربوى بكلية التربية بالمنيا - جامعة المنيا & د/ أحمد قطب محمد & $\wedge$ \\
\hline - جامعة علم النفس التريوى بكلية الدراسات العليا للتربية بالقاهرة & د/ أسماء توفيق مبروك & 9 \\
\hline - مارس علم النفس التريوى بكلية الدراسات العليا للتربية بالقاهرة & د/ دعاء أحمد محمد هريدى & 1. \\
\hline - جامعة علم النفس التريوى بكلية الدراسات العليا للتربية بالقاهرة & د/ عاصم عبدالمجيد كامل أحمد & 11 \\
\hline - مارس علم النفس التريوى بكلية الدراسات العليا للتربية بالقاهرة & عطيفى محمد عاطف عبدالحفيظ & ir \\
\hline مدرس علم النفس التريوى بكلية التربية بالمنيا - جامعة المنيا & د/ مصطفى على خلف & ir \\
\hline
\end{tabular}


تقتين مقياس ما وراء الفهم في الرياضيات لاى طلاب الصف الأول الثانوي

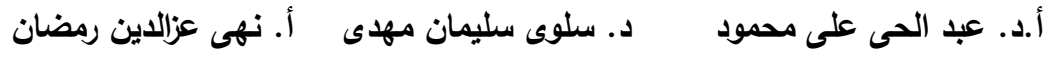

ملحق(r)

مقياس ما وراء الفهم

Metacomprehension scale

تعليمات المقياس

املأ البيانات التالية قبل البدء في الإجابة:

الجنس: ...........................

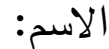

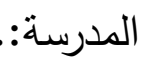

- يهدف هذا المقياس إلى قياس حكمك على فهمك فى مادة الرياضيات.

- يتكون المقياس من (إ) عبارة أمام كل منها ثلاث اختيارات هى (دائماً -

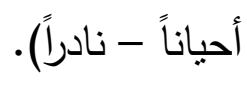

- اقرأ كل عبارة بعناية ودقة ثم ضع علامة ( ( ) فى الخانة المقابلة لها بحيث تكون معبرةً عن رأيك الثخصى وذللك فى نفس الورقة.

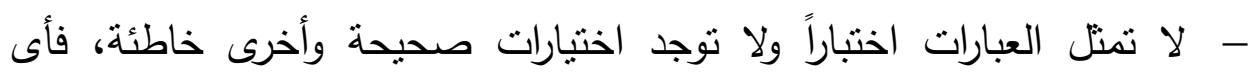
اختيار صحيح طالما يعبر عن وجهة نظرك. - - لا تترك أى عبارة دون إجابة ولا تضع علامة ( ل

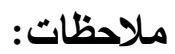

ليس هنالك وقت محدد للإجابة. تأكد من كتابة البيانات.

جميع هذه البيانات سربة، ولن بطلّع عليها سوى الباحثة، ولن تُشتخدم إلا فىى

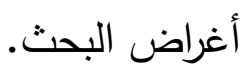
والباحثة تثكر لكم مسبقاً حسن تعاونكم،،

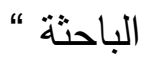


تقتين مقياس ما وراء الفهم في الرياضيات لاى طلاب الصف الأول الثانوي

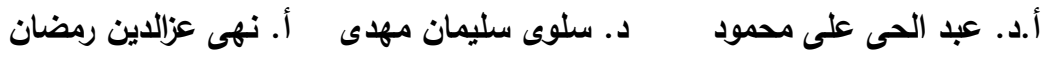

\begin{tabular}{|c|c|c|c|c|}
\hline نادراً & أحياناً & دائماً & 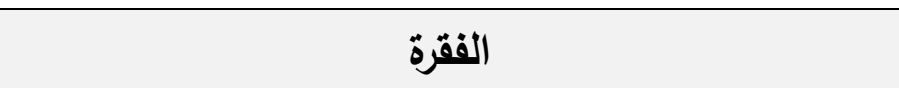 & s \\
\hline & & & يمكننى فهم أى مسألة رياضية. & 1 \\
\hline & & & أجيد فهم المسائل الرياضية. & r \\
\hline & & & أنظم أفكارى لحل مسألة رياضية بشكل متسلسل. & r \\
\hline & & & أتحدث بصوت مسموع مع نفسى عند حل مسألة رياضية. & $\varepsilon$ \\
\hline & & & أحافظ على تسلسل خطوات حل أى مسألة رياضية. & 0 \\
\hline & & & ألتزم بالوقت المحدد لحل أى مسألة رياضية. & 7 \\
\hline & & & أتبع الخطة التى وضعتها لحل مسألة رياضية معينة. & $\checkmark$ \\
\hline & & & أعيد تنظيم خطوات الحل عذ ظهور صعويات فى حل مسألة رياضية. & $\wedge$ \\
\hline & & & حل أتجنب ما أقع فيه من أخطاء فى حل مسائل رياضية سابقة عذد & 9 \\
\hline & & & أراجع إجاباتى بعد كل خطوة من خطوات الحل. & 1 . \\
\hline & & & أتاكد من فهمى لمحتوى المسألة قبل حلها. & 11 \\
\hline & & & أسأل نفسى بإستمرار إذا كنت أتبع الخطوات الصحيحة للحل. & it \\
\hline & & & أتحقق من وصولى للإجابة الصحيحة عند حل المسائل الرياضية & r \\
\hline & & & أقيم طريقة حلى للمسائل الرياضية بكتابة إيجابياتها وسلبياتها. & $1 \varepsilon$ \\
\hline & & & وأعيد حل المسائل الرياضية بأكثر من طريقة لمقارنة النتائج & 10 \\
\hline & & & أقر لنفسى الدرجة التى أستحقها بعد حل أى مسألة رياضية. & 17 \\
\hline & & & أقوم بتقدير مدى فائدة الطريقة التى أستخدمها أثناء قيامى بحل & iv \\
\hline & & & أستطيع الحكم على مدى فهمى للارس بعد استذكاره. & 11 \\
\hline & & & أعيد صياغة المسألة بالطريقة التى تسهل فهمها. & 19 \\
\hline & & & أرتب المعطيات بطريقة منظمة قبل تنفيذ الحل. & r. \\
\hline
\end{tabular}


تقتين مقياس ما وراء الفهم في الرياضيات لاى طلاب الصف الأول الثانوي

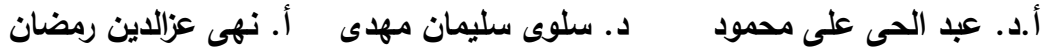

\begin{tabular}{|c|c|c|c|c|}
\hline 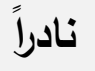 & أحياناً & دائماً & 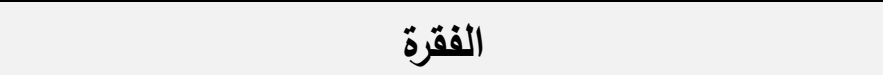 & م \\
\hline & & & أتصور خطة لخطوات الحل فى ذهنى قبل تنفيذه. & $Y_{1}$ \\
\hline & & & أقوم بتقسيم الوقت على كل خطوة من خطوات الحل. & rt \\
\hline & & & أقوم بتوليد أفكار بديلة لمواجهة صعويات حل المسائل الرياضية. & rt \\
\hline & & & أعيد كتابة خطوات حل المسألة الرياضية عندما يصعب حلها. & Y纟 \\
\hline & & & أراجع المعلومات التى تساعدنى على حل مسألة رياضية. & ro \\
\hline & & & أستخدم عدة طرق لحل المسائل الرياضية الصعبة. & rT \\
\hline & & & ألقوم بفصة والسهلة. المسائل الرياضية للتمييز بين المسائل الرياضية & rV \\
\hline & & & بعد دراستى أضع ملخصاً لما قت باستذكاره. & r人 \\
\hline & & & أحاول عمل علاقات بين الأفكار فى كتابى الدراسى. & rq \\
\hline & & & 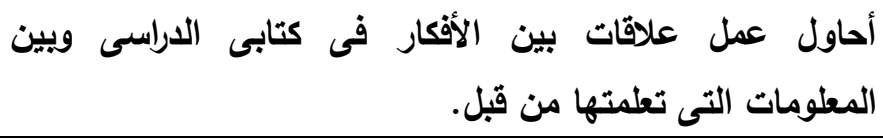 & r. \\
\hline & & & أستطيع استنتاج العلاقات اللازمة لحل المسائل الرياضية. & ו ו \\
\hline & & & أجيد فهم الألغاز الرياضية. & rt \\
\hline & & & أدرك نقاط القوة والضعف فى قدراتى المتعلقة بالرياضيات. & r \\
\hline & & & أحدد ما أعرفه وما لا أعرفه فى المسألة الرياضية. & rs \\
\hline & & & أقرأ المسائل الرياضية الصعبة بتأنًّ حتى أستطيع فههها. & o \\
\hline
\end{tabular}

